\title{
Selective targeting of melanoma by PEG-masked protein-based multifunctional nanoparticles
}

This article was published in the following Dove Press journal:

International Journal of Nanomedicine

15 March 2012

Number of times this article has been viewed

\section{Luca Vannuccil,* \\ Elisabetta Falvo 2,* \\ Manuela Fornara ${ }^{3}$ \\ Patrizio Di Micco ${ }^{4}$ \\ Oldrich Benada' \\ Jiri Krizan' \\ Jan Svoboda' \\ Katarina Hulikova-Capkova' \\ Veronica Morea $^{3}$ \\ Alberto Boffi ${ }^{4,5}$ \\ Pierpaolo $\mathrm{Ceci}^{3}$ \\ 'Institute of Microbiology, Academy of Sciences of the Czech Republic, VVI, Prague, Czech Republic; ${ }^{2}$ Regina Elena Cancer Institute, Pharmacokinetic/ \\ Pharmacogenomic Unit, ${ }^{3}$ National Research Council of Italy, Institute of Molecular Biology and Pathology, ${ }^{4}$ Department of Biochemical Sciences "A Rossi Fanelli”, University of Rome "Sapienza", ${ }^{5}$ Center for Life Nano Science at Sapienza, Italian Institute of Technology, Rome, Italy \\ *These two authors contributed equally to this work}

\section{Video abstract}

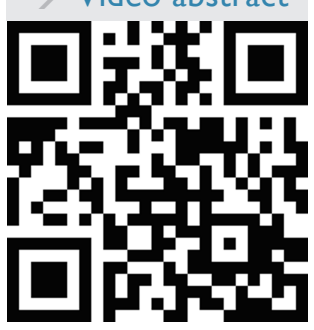

Point your smartphone at the $\mathrm{QR}$ code to the left. If you have a QR code reader the video abstract will appear. Or use: http:/bitly yZBwLu

Correspondence: Pierpaolo Ceci National Research Council of Italy, Institute of Molecular Biology and Pathology, c/o Department of Biochemical Sciences "A Rossi Fanelli”, University of Rome "Sapienza", P le Aldo Moro 5, Rome 00 I85, Italy Tel +39064990910

Fax +3906 4440062

Email pierpaolo.ceci@cnr.it
Background: Nanoparticle-based systems are promising for the development of imaging and therapeutic agents. The main advantage of nanoparticles over traditional systems lies in the possibility of loading multiple functionalities onto a single molecule, which are useful for therapeutic and/or diagnostic purposes. These functionalities include targeting moieties which are able to recognize receptors overexpressed by specific cells and tissues. However, targeted delivery of nanoparticles requires an accurate system design. We present here a rationally designed, genetically engineered, and chemically modified protein-based nanoplatform for cell/tissue-specific targeting.

Methods: Our nanoparticle constructs were based on the heavy chain of the human protein ferritin (HFt), a highly symmetrical assembly of 24 subunits enclosing a hollow cavity. HFt-based nanoparticles were produced using both genetic engineering and chemical functionalization methods to impart several functionalities, ie, the $\alpha$-melanocyte-stimulating hormone peptide as a melanoma-targeting moiety, stabilizing and HFt-masking polyethylene glycol molecules, rhodamine fluorophores, and magnetic resonance imaging agents. The constructs produced were extensively characterized by a number of physicochemical techniques, and assayed for selective melanoma-targeting in vitro and in vivo.

Results: Our HFt-based nanoparticle constructs functionalized with the $\alpha$-melanocytestimulating hormone peptide moiety and polyethylene glycol molecules were specifically taken up by melanoma cells but not by other cancer cell types in vitro. Moreover, experiments in melanoma-bearing mice indicate that these constructs have an excellent tumor-targeting profile and a long circulation time in vivo.

Conclusion: By masking human HFt with polyethylene glycol and targeting it with an $\alpha$-melanocyte-stimulating hormone peptide, we developed an HFt-based melanoma-targeting nanoplatform for application in melanoma diagnosis and treatment. These results could be of general interest, because the same strategy can be exploited to develop ad hoc nanoplatforms for specific delivery towards any cell/tissue type for which a suitable targeting moiety is available.

Keywords: multifunctional nanoparticles, ferritin, nanoplatform, cancer-targeting, melanoma

\section{Introduction}

Development of multifunctional nanoparticles for nanomedicine applications, such as cell/tissue-specific delivery, biomedical imaging and therapy, has recently gained wide popularity. ${ }^{1-4}$ Various types of materials, including synthetic polymers and lipids, have been increasingly utilized as platforms for nanoparticle synthesis. ${ }^{1,5}$ Despite the large number of bioconjugation techniques available, the attainment of multifunctional nanoprobes endowed with desired bioactivity, targeting specificity, 
and stability remains a challenge. Approaches using protein-cage structures, such as proteins belonging to the ferritin family, are novel and very promising. ${ }^{6,7}$ Apoferritin is a highly symmetrical multimeric protein consisting of 24 subunits that self-assemble into a shell-like molecule enclosing a hollow cavity, with external and internal diameters of $12 \mathrm{~nm}$ and $8 \mathrm{~nm}$, respectively. ${ }^{8,9}$ Ferritin structure and size are precisely controlled at the atomic level, because ferritin monomers are gene products. As a consequence, ferritin proteins guarantee excellent size and shape control in metal nanoparticle synthesis, and several materials, such as $\mathrm{Fe}_{3} \mathrm{O}_{4}, \mathrm{Co}_{3} \mathrm{O}_{4}, \mathrm{Mn}_{3} \mathrm{O}_{4}, \mathrm{Pt}$, CoPt, $\mathrm{Pd}$, $\mathrm{CdS}, \mathrm{CdSe}, \mathrm{ZnSe}, \mathrm{CaCO}_{3}, \mathrm{Ag}$, and $\mathrm{Au}$ have been produced within the internal cavity of ferritin proteins. ${ }^{10-18}$ The small size of ferritins $(<20 \mathrm{~nm})$ increases the chances of larger nanoparticles passing human body barriers and reaching specific targets. Indeed, the dimensions of the nanoparticles, which must be small enough to penetrate capillary fenestrations and large enough to avoid rapid clearance through the kidney (the ideal diameter being lower than 50-60 nm and greater than 6-8 nm, respectively), ${ }^{19,20}$ are one of the key prerequisites for efficient targeted delivery, together with a long-circulating capability of the carrier and high specificity of the selector towards the target receptor. Additionally, the exceptional stability of the ferritin cage structure over a wide range of temperatures (up to $80^{\circ} \mathrm{C}-100^{\circ} \mathrm{C}$ ) and $\mathrm{pH}$ conditions (3-10) and high expression levels as a recombinant protein in efficient heterologous systems like Escherichia coli cells (100$200 \mathrm{mg} / \mathrm{L}$ in laboratory scale) allow the apoferritin protein to be produced on a large-scale, at high yield (gram or even kilogram) and at low cost, which is useful for industrial scaleup purposes. Further, human ferritin is a physiological protein that has high solubility and stability in water, blood, and buffers, as well as low toxicity, all of which are desirable features for in vivo applications in humans. ${ }^{21,22}$ Several groups have reported that ferritins are effective templates for loading either imaging agents for magnetic resonance imaging or positron emission tomography (PET) ${ }^{21-24}$ as well as metal-based drugs in their internal cavity. ${ }^{25}$ Finally, ferritin proteins possess distinct interfaces (ie, an internal one facing the cavity and an external one facing the solvent) endowed with a variety of chemical groups, eg, primary amines, carboxylates, and thiols, which can be linked either genetically and/or chemically with different functionalities for targeted delivery of imaging and/or therapeutic agents. ${ }^{22,24}$ For all these reasons, there has been widespread interest in the possibility of using ferritin-based nanoplatforms for selective targeting.

In previous reports, the heavy chain of human ferritin (HFt) has been genetically conjugated with an arginineglycine-aspartate (RGD)-containing tumor targeting peptide, which is recognized by a large number of integrin molecules expressed by melanoma, glioma, and other tumors, as well as by normal cells. ${ }^{24,26}$ These RGD-containing HFt constructs have shown promising selectivity towards melanoma in in vitro experiments because compared with unconjugated HFt they have a threefold higher ability to bind melanoma cells, but show no difference in $\mathrm{T}$ lymphocyte binding. ${ }^{26}$ In spite of these encouraging results, only one study has reported on the application of HFt-based constructs bearing a targeting moiety for a physiological receptor in vivo. ${ }^{24}$ In this study, the localization of an RGD-containing HFt in an animal model of glioma was approximately $6 \%$ of the injected dosage, $2 \%$ of which was ascribed to the presence of the RGD targeting moiety and $4 \%$ to the enhanced permeability and retention effect of the tumor tissue. However, massive accumulation of the construct was observed in the liver, which appeared to be significantly greater than in the tumor. ${ }^{26}$

The enhanced permeability and retention effect has been shown to allow nanoparticles to accumulate at tumor sites in concentrations 5-10 times higher than in normal tissue within 1-2 days. ${ }^{27}$ However, this effect is counteracted both by fast clearance from plasma (10-60 minutes), which has been observed in rats, dogs, and rabbits after intravenous injection of liver ferritin, and by the presence of ferritin receptors on several cell types, including macrophages, ${ }^{21,28-32}$ which determines ferritin removal from the circulation by the reticuloendothelial or mononuclear phagocytic systems.

To overcome these limitations and increase the circulation time of ferritin, as well as target specificity with respect to previously reported HFt constructs, we developed chemically and genetically engineered HFt-based nanoparticles aimed at specifically targeting melanoma cancer cells and tissues, while minimizing nonspecific binding versus other human cells (Scheme 1). To achieve these goals, the following strategy was adopted. First, HFt nanoparticles were genetically linked to $\alpha$-melanocyte-stimulating hormone $(\alpha-\mathrm{MSH})$, which had not been exploited previously as a targeting moiety for HFt constructs. The MSH peptide binds to melanocortin receptors that are overexpressed by melanoma cells and metastases, and expressed to a lower extent only by melanocytes. As a consequence, it is expected to be significantly more selective than the RGD peptide 


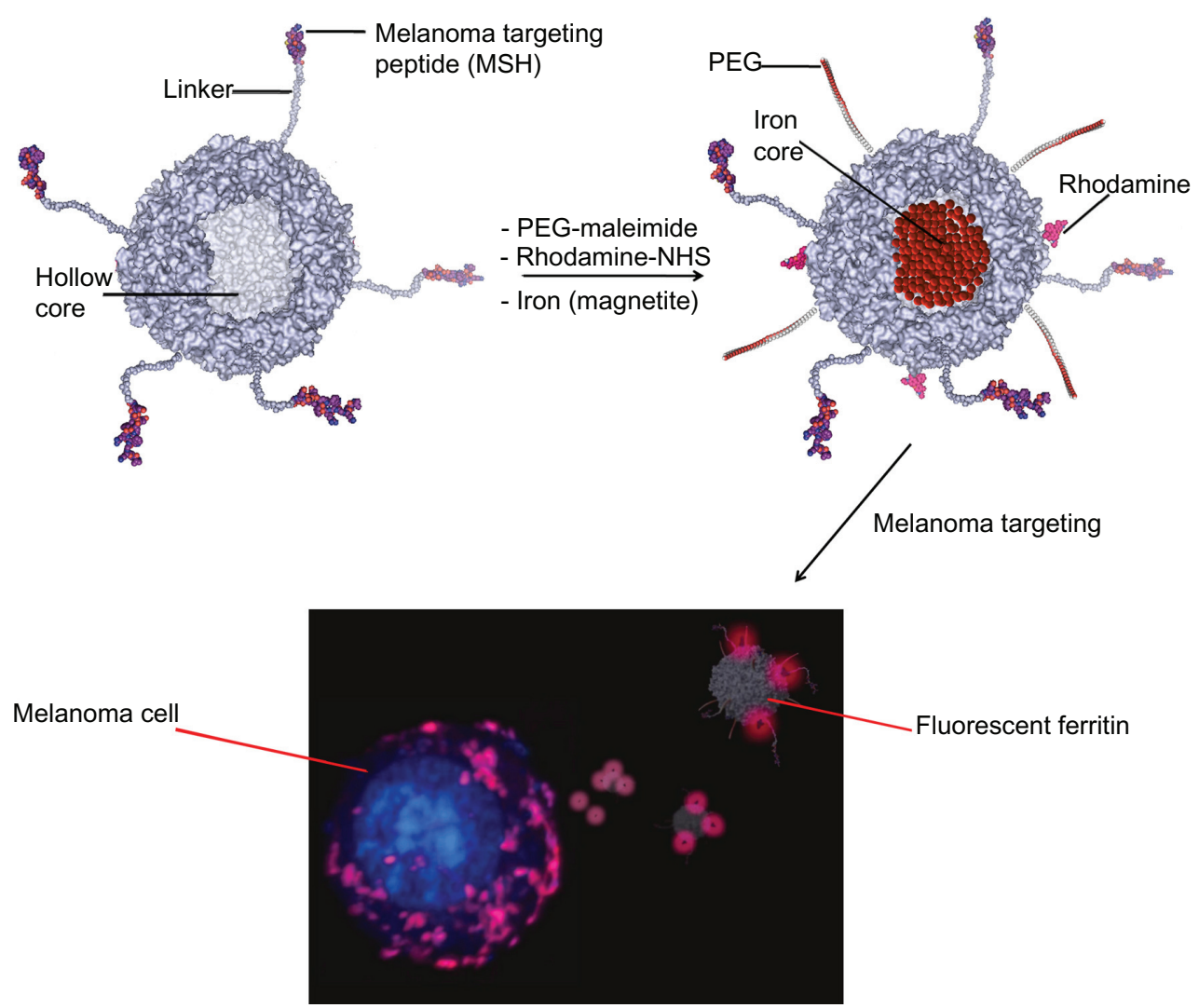

Scheme I Top: design of an HFt-based nanoplatform for melanoma targeting. The HFt protein has been genetically functionalized (left) with a melanocyte-stimulating hormone peptide joined to the $\mathrm{N}$-terminus of each of the 24 subunits by a linker peptide (only five of the 24 derivatized $\mathrm{N}$-termini are shown, for clarity). Additionally, chemical derivatization (right) has been performed to provide the HFt protein with novel functionalities for targeted delivery of imaging and therapeutic agents (polyethylene glycol, rhodamine, metal iron). Bottom: analysis of melanoma cells by confocal laser scanning microscopy. The shown confocal image demonstrates binding and uptake of HFt-based nanoparticles after in vitro incubation (60 minutes).

Abbreviation: $\mathrm{HFt}$, human protein ferritin.

linked to HFt in previous studies, in that the RGD moiety is recognized by a large number of integrin molecules, which are expressed by both normal and tumor cells. Additionally, polyethylene glycol (PEG) molecules were conjugated with the HFt surface, with the aim of masking the protein from its physiological receptors. HFt masking by PEGylation, which has not been implemented in previous studies of HFt-based constructs, is aimed at decreasing uptake of HFt by the reticuloendothelial and mononuclear phagocytic systems, resulting in an increased blood circulation time. ${ }^{27}$ Moreover, PEGylation is an effective method for preventing putative responses by the immune system, which would be elicited if the nanoparticles were sensed as foreign agents, in spite of the fact that both the HFt protein and MSH peptide components are extracellular and of human origin.

To assess the targeting specificity of our HFt-MSHPEG constructs, we carried out in vitro experiments using both melanoma and control cells, with wild-type HFt and HFt-PEG as controls. Additionally, we investigated the specificity and circulation time of the HFt-MSH-PEG constructs in melanoma-bearing mice, using wild-type HFt as a control.

The data reported herein demonstrate that the HFtMSH-PEG constructs were specifically taken up by melanoma cells but not by other tumor cells in vitro, and that the ability of HFt-MSH-PEG to bind to, and be internalized by melanoma cells is significantly higher than that of HFtPEG nanoparticles, which are devoid of the targeting MSH moiety, and of wild-type HFt. If the MSH moiety endows HFt with melanoma-targeting ability, the presence of PEG efficiently shields HFt from its cell receptors, because the uptake of both HFt-PEG and HFt-MSH-PEG by colon cancer cells is significantly lower than that of wild-type HFt.

In agreement with our in vitro results, studies performed using a melanoma animal model in vivo showed that the HFt-MSH-PEG nanoparticles accumulated to a large extent at the tumor sites whereas accumulation of wild-type $\mathrm{HFt}$ was negligible, and that this accumulation effect appears 
to be specific for the tumor when compared with the other tissues analyzed. Further, HFt-MSH-PEG had a higher circulation time than wild-type HFt, most likely because of the presence of PEG.

Thus, the strategy adopted to develop melanoma-targeting HFt-MSH-PEG nanoparticles appears to be suitable for the development of targeted imaging agents for magnetic resonance imaging, PET, and fluorescence imaging, as well as for targeted delivery of therapeutic agents in cancer therapy.

\section{Materials and methods Cloning, overexpression, and purification of HFt-based nanoparticles}

The expression vector, pET-17b, containing the $H F t-M S H$ gene, was purchased from GeneArt AG (Bavaria, Germany). Gene synthesis was performed taking into consideration the codon optimization for high level expression in E. coli. E. coli BL21 (DE3) cells harboring the recombinant HFt-MSH plasmid were grown to $\mathrm{OD}_{600} 3.0$ at $30^{\circ} \mathrm{C}$ in $1 \mathrm{~L}$ of ampicillincontaining liquid Luria-Bertani broth medium (Sigma-Aldrich, Milan, Italy). The cells were harvested by centrifugation at $16,000 \mathrm{rpm}$ for 20 minutes and suspended in $50 \mathrm{mM}$ Tris- $\mathrm{HCl}$, $0.5 \mathrm{mM}$ dithiothreitol, $1 \mathrm{mM}$ ethylenediamine tetra-acetic acid, and $300 \mathrm{mM} \mathrm{NaCl}$ at $\mathrm{pH} 7.5$, and disrupted by sonication in the presence of $1 \mathrm{mM}$ phenylmethylsulfonyl fluoride. The lysate was then centrifuged at $16,000 \mathrm{rpm}$ for $40-45$ minutes at $6^{\circ} \mathrm{C}$. The pellet was washed twice with $100 \mathrm{mM} \mathrm{N}$-cyclohexyl3-aminopropanesulfonic acid ( $\mathrm{pH} 10.5)$ and then centrifuged at $16,000 \mathrm{rpm}$ for 10 minutes at $6^{\circ} \mathrm{C}$ to recover the HFt$\mathrm{MSH}$ protein from the membrane-containing fraction. After each centrifugation step, the supernatants were collected and combined with each other. The solution obtained was dialyzed overnight against Tris $30 \mathrm{mM}, 0.6 \mathrm{M} \mathrm{NaCl}, \mathrm{pH}$ 7.8 at room temperature. HFt-MSH precipitates under these high salt conditions. The pellet was resuspended in Milli-Q water (Millipore, Billerica, MA), sterile-filtered, and stored at $4^{\circ} \mathrm{C}$. Typical yields were $150-200 \mathrm{mg}$ of pure protein per liter of culture. Human apo-HFt was provided by MoLiRom (Rome, Italy).

\section{Protein stability measurements}

The thermal stability of wild-type HFt and HFt-MSH was assessed in the temperature range of $30^{\circ} \mathrm{C}-100^{\circ} \mathrm{C}$ by following the circular dichroism signal at $222 \mathrm{~nm}$ to monitor the thermal unfolding process. A Jasco J-715 spectropolarimeter was used. Temperature was varied in steps of $1{ }^{\circ} \mathrm{C}$ per minute. The protein, at $1 \mathrm{mg} / \mathrm{mL}$ in Milli-Q water, was kept in stoppered $0.1 \mathrm{~cm}$ quartz cells.
The ability of HFt-MSH to dissociate and reassociate reversibly as a function of $\mathrm{pH}$ was also assessed. The protein solution was adjusted to $\mathrm{pH} 2.0$ by addition of $\mathrm{HCl} 0.1 \mathrm{M}$, and the $\mathrm{pH}$ was kept constant for about 15 minutes to ensure that dissociation of HFt-MSH was complete. The $\mathrm{pH}$ value was then adjusted to 7.5 by adding $\mathrm{NaOH} 0.1 \mathrm{M}$. The resulting solution was stirred at room temperature for 1 hour and checked for HFt-MSH oligomerization by size exclusion chromatography. The size exclusion chromatography experiments were performed using a Superose 6 gel filtration column connected to a GE Healthcare FPLC system Unicorn Akta purifier (GE Healthcare, Milan, Italy) equilibrated with phosphate-buffered saline at $\mathrm{pH}$ 7.5.

\section{Preparation of PEGylated proteins}

HFt and HFt-MSH solutions ( $2 \mathrm{mg} / \mathrm{mL}$ ) were incubated with $1.0 \mathrm{mM}$ of $5 \mathrm{kDa}$ methoxypolyethylene glycol maleimide (Sigma-Aldrich), in $20 \mathrm{mM}$ Tris- $\mathrm{HCl}$ at $\mathrm{pH} 7.2$ and room temperature for about 2 hours under stirring. Subsequently, samples were filtered and exchanged 4-5 times with $\mathrm{H}_{2} \mathrm{O}_{\mathrm{dd}}$ using $30 \mathrm{kDa}$ Amicon Ultra-15 centrifugal filter devices (Millipore) to remove the excess reagents. The PEGylated samples were sterile-filtered and stored at $4{ }^{\circ} \mathrm{C}$.

\section{Size exclusion chromatography and dynamic light scattering}

The size exclusion chromatography experiments were performed using a Superose 6 gel filtration column equilibrated with phosphate-buffered saline at $\mathrm{pH}$ 7.5. Dynamic light scattering experiments were carried out using a Zetasizer Nano S (Malvern Instruments, Worcestershire, UK) equipped with a $4 \mathrm{~mW}$ He-Ne laser (633 nm). Measurements were performed at $25^{\circ} \mathrm{C}$, with an angle of $173^{\circ}$ from the incident beam. Peak intensity analyses were used to determine the average hydrodynamic diameters ( $Z$-average diameter) of the scattering particles. Results are the average of at least five measurements. All samples were prepared at $1 \mathrm{mg} / \mathrm{mL}$ in filtered $\mathrm{H}_{2} \mathrm{O}_{\mathrm{dd}}$. All traces for the size exclusion chromatography and dynamic light scattering experiments were analyzed using Origin 8.0 (Originlab Corporation, Northampton, MA).

\section{Mass spectrometric analysis and sample preparation}

HFt-MSH and HFt-MSH-PEG samples at a concentration of $1 \mathrm{mg} / \mathrm{mL}$ were used in a native form and digested using trypsin enzyme (sequencing grade, Promega, Madison, WI). Trypsin digestion was performed overnight at $37^{\circ} \mathrm{C}$ in $25 \mathrm{mM}$ ammonium bicarbonate at a $\mathrm{pH}$ of 8.0, with a trypsin:HFt 
construct molar ratio of 1:50. The digested HFt construct was loaded onto the target plate and mixed immediately with an equal volume of $\alpha$-cyanohydroxycinnamic acid in 50\% acetonitrile and $0.1 \%$ trifluoroacetic acid (Sigma-Aldrich). The samples were analyzed using a matrix-assisted laser desorption/ionization (MALDI) time-of-flight Applied Biosystems/MDS Sciex 4800 Plus MALDI TOF/TOFTM analyzer (Monza, Italy). The base peak in the MALDI TOF mass spectrum (m/z 1056.5) was isolated and fragmented in the TOF/TOF mass spectrometer. Analysis of the tandem mass spectrum showed product ions (b and y series). Data analysis was carried out using the Data Explorer 4.0 software (Applied Biosystems).

\section{Fourier transform infrared spectroscopic analysis}

HFt-MSH and HFt-MSH-PEG samples for Fourier transform infrared spectroscopic measurements were used at $3 \mathrm{mg} / \mathrm{mL}$ in $\mathrm{H}_{2} \mathrm{O}_{\text {dd }}$ and layered upon the $\mathrm{ZnSe}$ crystal. The protein solutions $(250 \mu \mathrm{L})$ were layered on the $\mathrm{ZnSe}$ plate, dried under a nitrogen stream, and placed in an atmosphere saturated with water vapor in a glove box for 24 hours in order to obtain a fully hydrated sample. Attenuated total reflectance-Fourier transform infrared spectroscopic measurements were carried out on a Magna 760 Nicolet instrument equipped with an MCT/A detector (ThermoFisher Scientific Inc, Illkirch Cedex, France). ZnSe ARK plates equipped with a thermal ARK temperature controller (ThermoFisher Scientific Inc) were used as internal reflection elements. A sealed, volatile solvent cover was used during the measurements in order to maintain constant hydration of the sample. Typically, 128 scans were acquired at $4 \mathrm{~cm}^{-1}$ resolution, two levels of zero filling, and $25^{\circ} \mathrm{C}$. For each spectrum, the background was acquired on the empty attenuated total reflectance plate.

\section{Magnetic HFt preparation and transmission electron microscopic analysis}

Magnetite (or maghemite) was incorporated into the HFtMSH using a method described elsewhere. ${ }^{34}$ Briefly, iron incorporation experiments were carried out at $65^{\circ} \mathrm{C}$ on $1 \mathrm{mg} / \mathrm{mL}$ HFt-MSH samples in $5 \mathrm{mM}$ Hepes-NaOH at a $\mathrm{pH}$ of 8.5. Solutions of $\mathrm{FeSO}_{4}$ dissolved in $0.5 \mathrm{mM} \mathrm{HCl}$ were used as an iron source. During the course of the experiment, the reaction vessel was kept at $65^{\circ} \mathrm{C}$ under a positive nitrogen pressure, and $\mathrm{pH}$ was maintained dynamically at 8.5 with $100 \mathrm{mM} \mathrm{NaOH}$ using an automatic titrator (Titrino;
Metrohm AG, Herisau, Switzerland). Solutions of $\mathrm{FeSO}_{4}$ $15 \mathrm{mM}$ and $\mathrm{H}_{2} \mathrm{O}_{2} 5 \mathrm{mM}$ were added simultaneously at a constant rate $(0.5 \mathrm{~mL} / \mathrm{minute})$ using two peristaltic pumps. The theoretical iron loading factor was $4500 \mathrm{Fe}(\mathrm{II}) /$ protein. The protein and iron contents in the samples containing the magnetic nanoparticles were assessed by means of native electrophoresis on 1\% agarose gels and inductively-coupled plasma atomic emission spectroscopy.

HFt-MSH-enclosed magnetite/maghemite samples, in PEGylated or non-PEGylated form $(0.1 \mathrm{mg} / \mathrm{mL})$ were negatively stained $(0.1 \%$ of trehalose into $1 \%$ ammonium molybdate) on glow discharge-activated carbon-coated grids. ${ }^{35}$ Samples were viewed under a Philips CM100 electron microscope (Eindhoven, The Netherlands) at $80 \mathrm{kV}$. Digital images were recorded using a MegaView II slow scan camera at a primary magnification of $92,000 \times$.

\section{Protein structure analysis and modeling}

The atomic structure of HFt was downloaded from the Protein Data Bank (http://www.pdb.org). ${ }^{36}$ Protein structure visualization and modeling of the PEG chains, MSH peptide, and Gly/Ser-rich linker were performed using Insight II software (Accelrys Inc, San Diego, CA).

\section{Fluorescent labeling of proteins}

HFt-PEG and HFt-MSH-PEG solutions (2 mg/mL) were incubated with $1 \mathrm{mM}$ of 5(6)-carboxytetramethylrhodamine $\mathrm{N}$-succinimidyl ester $\left(\lambda_{\text {ex }} 552 \mathrm{~nm}, \lambda_{\text {em }} 575 \mathrm{~nm}\right.$; Thermo Scientific, Milan, Italy) in phosphate-buffered saline for 2 hours at $\mathrm{pH} 7.5$ and room temperature, with stirring in the dark. Subsequently, the samples were filtered, dialyzed, and exchanged with $\mathrm{H}_{2} \mathrm{O}_{\text {dd }}$ and phosphate-buffered saline, using $30 \mathrm{kDa}$ Amicon Ultra-15 centrifugal filter devices to remove excess reagents. The samples were sterile-filtered and stored at $4^{\circ} \mathrm{C}$ in the dark. The number of dye molecules linked per protein was determined by absorbance spectroscopy, in accordance with the manufacturer's instructions, applying the Beer-Lambert law. Briefly, the measurement was carried out using a $0.1 \mathrm{~cm}$ path length quartz cuvette at room temperature. The concentration of bound dye was calculated using the following equation: $\mathrm{c}($ dye $)=\mathrm{A}_{552 \mathrm{~nm}} /\left(\varepsilon_{\max } \times \mathrm{d}\right)$, where $\varepsilon_{\max }$ is 80,000 for rhodamine dye. The protein concentration is obtained in the same way from its absorbance value at $280 \mathrm{~nm}$, using an $\varepsilon$ of 25,900 and $18,910 \mathrm{M}^{-1} \mathrm{~cm}^{-1}$ for HFt$\mathrm{MSH}$ and wild-type HFt, respectively. Because rhodamine shows some absorption at $280 \mathrm{~nm}$, the measured absorbance $\mathrm{A}_{280}$ was corrected for the contribution of this dye (correction factor $=0.34$ ). 


\section{Cell culture and confocal microscopy on tumor cells in vitro}

The murine melanoma B16F10 cell line of C57BL/6 $\left(H-2^{b} / H-2^{b}\right)$ origin (ATCC, Manassas, VA) as well as human colorectal carcinoma HT29 cell line (ATCC) were cultivated in RPMI-1640 medium (Institute of Molecular Genetics, Prague, Czech Republic), supplemented with $0.05 \mathrm{mg} / \mathrm{mL}$ gentamicin, $2 \mathrm{mM}$ L-glutamine, $1 \mathrm{mM}$ sodium pyruvate, $0.05 \mathrm{mM} 2$-mercaptoethanol, and $10 \%$ heat-inactivated fetal calf serum (Gibco, Grand Island, NY), at $37^{\circ} \mathrm{C}$ in a $5 \% \mathrm{CO}_{2}$ humidified atmosphere.

B16F10 melanoma or HT29 human colorectal carcinoma cells in suspension $\left(1 \times 10^{6}\right.$ cells $\left./ 100 \mu \mathrm{L}\right)$ were incubated with fluorescent wild-type HFt, HFt-PEG, or HFt-PEG-MSH in H-MEMD culture medium. The HFt nanoparticle solutions $(100 \mu \mathrm{L})$ were added to $100 \mu \mathrm{L}$ of cell solution. The final concentration of HFt nanoparticles was $0.007 \mathrm{mg} / \mathrm{mL}$. The controls received only addition of medium without $\mathrm{HFt}$ nanoparticles. The cells were incubated at $37^{\circ} \mathrm{C}$ in $5 \%$ $\mathrm{CO}_{2}$ for 10 and 60 minutes. After incubation, the cells were fixed in $3.7 \%$ formaldehyde for 30 minutes and then washed three times with Dulbecco's phosphate-buffered saline. The cell nuclei were stained using Draq5. The confocal microscopy apparatus comprised a confocal laser scanning system (1-photon) Olympus FV1000 with an IX 81 inverted microscope, a Hamamatsu C9 100/13 EM-CCD digital camera, and an imaging analysis program (Flowview 10; Olympus, Tokyo, Japan). Confocal microscopy was performed at $20 \times$ and $40 \times$ original magnification and all images, obtained using FluoView FV1000 software (Olympus), were background-subtracted and normalized to maximal intensities of the fluorescent HFt nanoparticles. Uptake of HFt nanoparticles by the cells was assessed from the average of the percentages of positive cells in three randomly evaluated fields per sample at $20 \times$ magnification, using four samples for each type of treatment and cells.

\section{In vivo administration of $\mathrm{HFt}$ nanoparticles and confocal evaluation}

Male C57BL/6 mice aged 7-8 weeks were purchased from AnLab (Prague, Czech Republic) and housed in conventional conditions in our experimental animal facility, and adapted to the local conditions over 10 days with a standard diet and access to water ad libitum before inoculation with the melanoma cells. The mice were intradermally/subcutaneously inoculated in the lower back with $1 \times 10^{6} \mathrm{~B} 16 \mathrm{~F} 10$ melanoma cells per mouse suspended in $0.1 \mathrm{~mL}$ of culture medium. Ten days after inoculation with the melanoma cells, the animals developed bulky tumors at the site of injection (5-7 mm diameter). Under general anesthesia, slow intracardiac injection of $0.1 \mathrm{~mL}$ of the experimental fluorescent wild-type HFt or HFt-PEG-MSH $(0.5 \mathrm{mg})$ solution was performed. The animals were maintained for one hour under observation for possible secondary effects after awakening. The mice were sacrificed 24 hours after inoculation. A skin flap including the tumor and a liver sample were harvested. A thick tumor section, a sample of skin, and a thick liver section were mounted on a large coverglass for direct observation of rhodamine fluorescence in the tissue by confocal laser scanning microscopy (excitation filter $530-550 \mathrm{~nm}$ ) at $40 \times$ original magnification, as described earlier.

\section{Effect of HFt nanoparticles on immune cells in vivo}

Healthy mice were sacrificed 24 hours after injection of the HFt nanoparticles. Their spleens were collected and gently dissociated through a nylon mesh in H-MEMD medium to prepare single cell suspensions, and splenocytes were not gradient-separated to collect all leukocytes. Complete blood samples were pretreated with ACK lysing buffer to lyse the erythrocytes before specific staining. Leukocytes were characterized by fluorescence-activated cell sorting analysis using an antibody against the CD45 common marker. CD69 positive cells were evaluated by gating the leukocyte population into granulogates, lymphogates, and monogates, respectively, on an FSc-SSc plot.

The experiments had the approval of the ethics committee at the Institute of Microbiology, according to the Animal Protection Act of the Academy of Sciences of the Czech Republic and the European Convention for the Care and Use of Laboratory Animals.

\section{Plasma stability and circulation time of HFt nanoparticles}

The stability of the iron-containing wild-type HFt and HFtMSH-PEG in mouse plasma was determined by size exclusion chromatography. Samples of the HFt nanoparticles $(0.20 \mathrm{~mL}$, $10 \mathrm{mg} / \mathrm{mL}$ ) were incubated at $37^{\circ} \mathrm{C}$ with mouse plasma $(1.8 \mathrm{~mL})$ and collected as follows. Samples were withdrawn at hours $1,6,18,24$, and 48 , centrifuged at $13,000 \mathrm{rpm}$ for 30 minutes, and loaded onto a Superose 6 gel filtration column connected to a GE Healthcare FPLC system Unicorn Akta purifier in phosphate-buffered saline at a flow rate of $0.5 \mathrm{~mL} /$ minute. The presence of intact HFt nanoparticles was determined by simultaneously following the protein signal (absorbance at $280 \mathrm{~nm}$ ) and the iron cluster (absorbance 
at $405 \mathrm{~nm}$ ), and calculating the area of the elution peaks typical of HFt 24-mers using Unicorn 5.01 software (GE Healthcare).

To evaluate the circulation time of the wild-type HFt and HFt-MSH-PEG nanoparticles, $0.1 \mathrm{~mL}$ of nanoparticles $(1.0 \mathrm{mg})$ was injected into the tail veins of the mice. Blood $(0.5 \mathrm{~mL})$ was collected from each mouse before injection and at 3 minutes and 1, 3, 6, and 24 hours following injection. Plasma was obtained by centrifugation of the fresh blood, containing heparin as an anticoagulant, at 13,000 rpm for 45 minutes. Presence of HFt nanoparticles was quantified by Western blotting using both anti-MSH and anti-HFt antibodies. Polyacrylamide gel electrophoresis was performed under denaturing and reducing conditions. Plasma was diluted $2 \times$ in sample buffer to prevent precipitation of serum proteins during boiling. Diluted samples were then boiled for 5 minutes. Thereafter, $12 \%$ sodium dodecyl sulfate gels were run at $150 \mathrm{~V}$ for one hour. Gel electrophoresis proteins were transferred to polyvinyl difluoride membranes in transfer buffer $(25 \mathrm{mM}$ Tris$\mathrm{HCl}, 192 \mathrm{mM}$ glycine, and 20\% methanol, $\mathrm{pH} 8.3$ ) at $100 \mathrm{~mA}$ for 45 minutes. Thereafter, membranes were blocked overnight at $4^{\circ} \mathrm{C}$ in $10 \%$ blocking reagent (Boehringer Mannheim, Ludwigshafen, Germany). Subsequently, the membranes were incubated in $1 \%$ gelatin in Tris-buffered saline with a rabbit monoclonal antibody, anti-HFt (Abcam, Cambridge, UK) or a rabbit polyclonal antibody anti-MSH (Abcam). Both antibodies were diluted $1000 \times$. Primary antibodies were detected with horseradish peroxidase-conjugated rabbit antigoat IgG (SigmaAldrich), and signals were visualized using a luminol-based chemiluminescent substrate designed for use with peroxidaselabeled reporter molecules (LumiGlo ${ }^{\circledR}$, KPL, Gaithersburg, MD) and Kodak Scientific Imaging Film (Eastman Kodak Company, Rochester, NY).

\section{Results and discussion}

Our main aim was to obtain an HFt-based construct that was shielded against nonspecific uptake by human cells and possessed a satisfactory circulation time in the bloodstream, which is a key property for in vivo applications. Derivatization using an inert and uncharged material such as PEG appeared to be an adequate strategy, both to reduce nonspecific cell binding and prolong the circulation time in serum. Based on previous reports, we set the size of the PEG molecules at $5 \mathrm{kDa} \cdot{ }^{37}$ Following observation of the three-dimensional structure of human HFt, we decided to link PEG molecules to the thiol groups of the cysteine residues, given that the location of the exposed cysteine thiols on the surface of $\mathrm{HFt}$ is such that their PEGylation is not expected to interfere with subsequent derivatization of the $\mathrm{N}$-terminal region, and given that HFt has a relatively small number of cysteine side chains on the external surface (two per subunit, ie, 48 for the whole assembly), compared with other solvent-exposed reactive groups (ie, amines and carboxylates), allowing us to have tight control over the number of PEG molecules conjugated to the HFt shell. To obtain covalently bound HFt construct-PEG complexes, the HFt constructs were reacted with functionalized maleimide-PEG $5 \mathrm{kDa}$.

The PEGylation reaction was performed using both wild-type HFt and the HFt construct containing the melanoma-binding peptide sequence, $\alpha-\mathrm{MSH}$, genetically linked to the N-terminal region of HFt (HFt-MSH). The $\alpha$-MSH peptide was chosen for a number of reasons. Short amino acid polymers (peptides) have a target-binding ability comparable with that of larger molecules, such as antibodies. Due to their small size, peptides are also ideal for multiple modifications of nanoparticle constructs and generation of pluripotent nanoparticles. ${ }^{38}$ Moreover, $\alpha$-MSH binds to melanocortin receptors and, in particular, is a potent agonist of the melanocortin type 1 receptor (MCR1, overexpressed by many melanoma cells ${ }^{39}$ ) and binds to MCR1 with high affinity $\left(\mathrm{IC}_{50} 0.21 \mathrm{nmol} / \mathrm{L}\right){ }^{40}$ Importantly, more than $80 \%$ of human metastatic melanoma samples have been found to display MCR $1 .{ }^{41}$ Melanoma metastases are very aggressive, with a patient survival time of 3-15 months on average, and are the actual cause of mortality in patients with melanoma. ${ }^{42}$ Therefore, the development of a system containing a targeting peptide able to bind melanoma metastases is of critical importance. Gold nanoparticles linked onto an analogous synthetic peptide were recently shown to have reasonably selective tumor localization compared with the nonspecific PEGylated form. ${ }^{43}$ However, because of the synthetic peptide origin, a very long and expensive procedure including peptide synthesis and chemical conjugation to the nanoparticles was required to obtain the final constructs. In our case, a simple cost-effective genetic engineering approach was used to link the $\alpha$-MSH peptide (SYSMEHFRWGKPV) to the N-terminus of the HFt subunit, resulting in production of an HFt assembly containing 24 peptide copies. This HFt nanocage should, in principle, have increased affinity for the corresponding receptor compared with a molecule containing a single peptide unit (ie, the multivalence effect).

Each $\alpha$-MSH peptide was spatially separated from the HFt subunit N-terminus by an inert and flexible Gly/ Ser-containing sequence linker. The length of the linker was designed based on analysis of the crystal structure of human HFt (PDB ID: 3AJO) and modeling of PEG molecules of 
the chosen length to guarantee sufficient exposure of the targeting $\alpha$-MSH peptide on the HFt external surface in the presence of PEG.

The yields of purified recombinant HFt-MSH and wild-type $\mathrm{HFt}$ from E. coli cultivation were in the ranges of $150-200 \mathrm{mg} / \mathrm{L}$ and $80-100 \mathrm{mg} / \mathrm{L}$, respectively. The purification procedures used for HFt-MSH were much easier and faster with respect to HFt, and allowed us to obtain large amounts of pure and fully assembled protein within two days. The integrity of the HFt-MSH N-termini after protein purification and PEGylation was checked by MALDI mass spectrometry, which confirmed that the full-length amino acid sequence corresponding to the $\alpha$-MSH peptide plus linker was present at the protein N-termini (Supplementary Figure S1). The mass spectra also highlighted the presence of PEG molecules linked to the cysteine residues of the protein (Supplementary Figure S2). Effective protein PEGylation was also monitored by Fourier transform infrared spectroscopy. Typical PEG signals relative to the $(\mathrm{CH} 2-\mathrm{O}-\mathrm{CH} 2)$ moiety and to the methylene stretching modes were detected only in the PEGylated HFt-MSH-PEG sample (see Supplementary Figure S3). In turn, amide bands at $1952 \mathrm{~cm}^{-1}$, typical of alpha helical structures, were almost super imposable on the native and PEGylated proteins.

After incorporation of magnetite/maghemite, the HFtMSH was analyzed by transmission electron microscopy, which showed that the HFt-MSH construct retained the ability of wild-type HFt to encapsulate magnetic iron and adopted the expected spherical cage-like structures with an external diameter of $13 \pm 2.1 \mathrm{~nm}$, typical of wild-type HFt (Supplementary Figure S4). As expected, the shape of the PEGylated HFt constructs did not appear to be perfectly spherical due to the flexibility of the PEG molecules present on the protein surface (Figure 1).

The magnetic properties of the HFt-MSH construct, evaluated by zero-field-cooled and field-cooled magnetization experiments (data not shown), were very similar to those previously reported for magnetite/maghemite nanoparticles

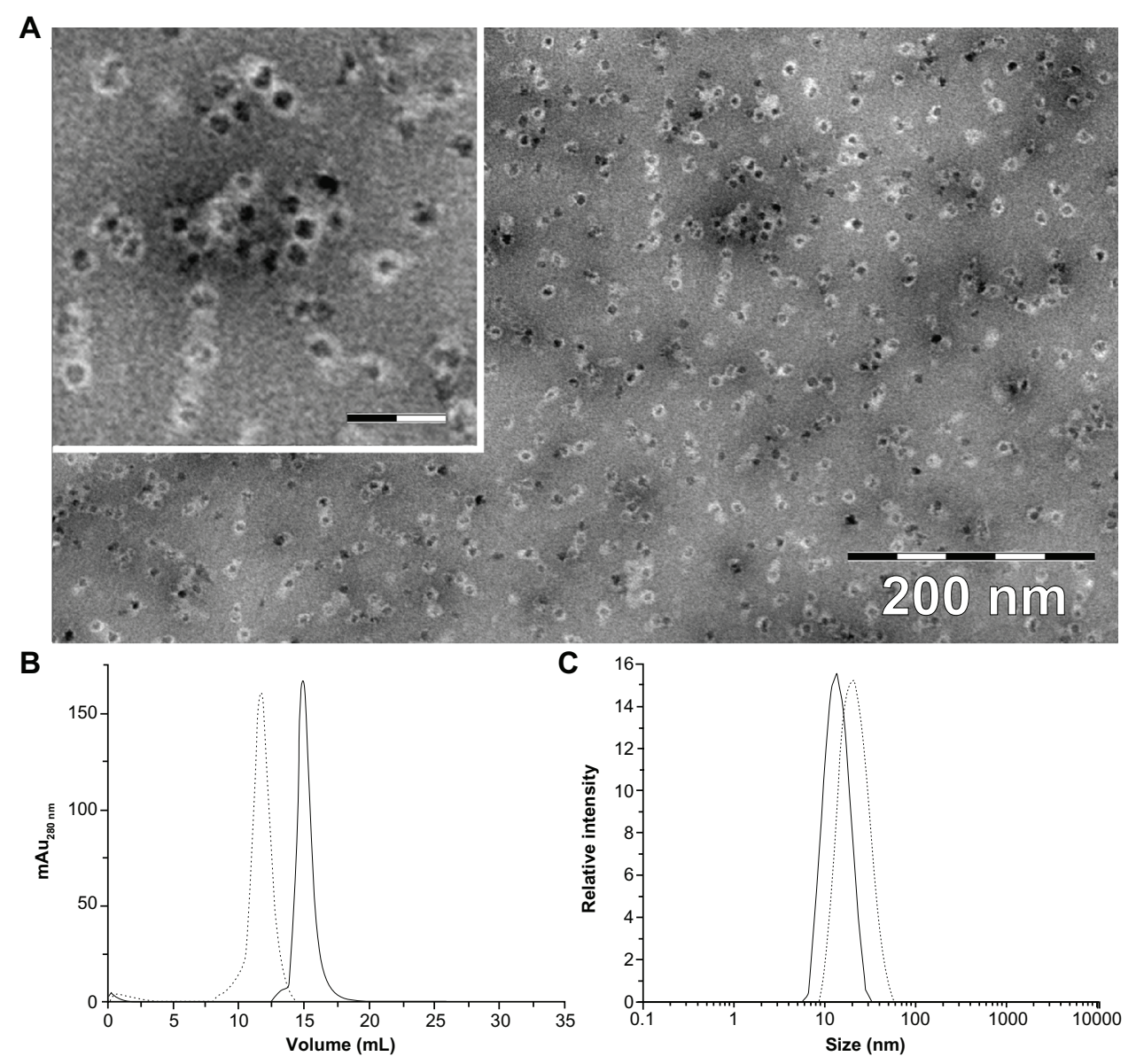

Figure I (A) Transmission electron microscopic image of magnetite/maghemite-containing HFt-MSH-PEG showing the metallic core (black) surrounded by the HFt shell (white). Inset: $2.5 \times$ magnified image, the scale bar represents $32 \mathrm{~nm}$. (B) Size-exclusion chromatography and (C) dynamic light scattering profiles of HFt-MSH before (solid line) and after (dotted lines) the PEGylation reaction.

Abbreviations: HFt, human protein ferritin; PEG, polyethylene glycol; MSH, melanocyte-stimulating hormone peptide. 
enclosed in different ferritin cages. ${ }^{37}$ The HFt-MSH sample had a loading factor of 3900 metal atoms per protein molecule, as assessed by inductively coupled plasma analysis. This number is close to the maximum loading capacity of the protein, which is around 4000 atoms, and is relevant in view of the potential uses of HFt-based nanoparticles as magnetic resonance imaging agents, which require a high enough amount of iron atoms to provide a detectable signal.

Size exclusion chromatography and dynamic light scattering was performed to estimate the diameter and polydispersity of the PEGylated (HFt-PEG and HFt-MSH-PEG) samples. All samples were found to be quite monodispersed in solution (Figure $1 \mathrm{~B}$ and $\mathrm{C}$, and Supplementary Figure S5). Both experiments indicate that non-PEGylated and PEGylated samples have a significant difference in size (mean diameters 13.0 and $20.0 \mathrm{~nm}$, respectively), implying elevated efficiency of the PEGylation reaction.

The aforementioned results indicate that, even after the addition of more than 30 amino acids to the $\mathrm{N}$-terminal region of each protein subunit, HFt maintained the characteristic 24-mer cage architecture, the ability to incorporate iron derivatives, the ability to undergo $\mathrm{pH}$-induced dissociation and reassembly (Supplementary Figure S6), and high thermal stability. Indeed, HFt-MSH showed even higher thermal stability than wild-type HFt in circular dichroism experiments (Supplementary Figure S7).

The PEGylated derivatives, HFt-PEG and HFt-MSHPEG, were labeled with NHS-rhodamine, an amine-reactive fluorescent reagent that absorbs green visible light (552 nm) and emits orange-red visible light $(575 \mathrm{~nm})$. This permitted us to trace the localization of our constructs on the surface of and inside the target cells (see below). Rhodamine-labeled HFt nanoparticles were purified from free dye by dialysis and centrifugal filter devices. The number of dye molecules linked per protein was determined to be about $0.9 /$ subunits (22.0/protein cage) for both HFt-PEG and HFt-MSH-PEG by absorbance spectroscopy (see Materials and methods section).

To investigate the targeting efficacy of the HFt-MSH-PEG constructs and to verify whether we succeeded in reducing their nonspecific binding to cancer cells, we compared their ability to target B16F10 melanoma cells versus a different type of cancer cells.

Cells incubated at different times with either $10 \mathrm{nM}$ rhodamine-labeled wild-type HFt, HFt-PEG, or HFt-MSHPEG were imaged using confocal microscopy. In agreement with previous findings, ${ }^{25,36}$ wild-type human HFt bound both melanoma cells and human HT29 colon carcinoma cells, as shown by the presence of a number of red particle clusters on the cell surface (Supplementary Figures S8 and S9), indicating that it was recognized nonspecifically by different cell types. Conversely, none or very few of these clusters were observed in the case of HFt-PEG (Figure 2B), indicating that derivatization with PEG molecules effectively shields the HFt molecule from its receptors on melanoma cells. Remarkably, in the presence of HFt-MSH-PEG, large numbers of clusters of small red particles were easily detected on both the surface and in the cytoplasm of melanoma cells (Figure 2A) whereas none or very few fluorescent clusters were present inside or on the surface of HT29 cells (Figure 2C). The relative percentages of cancer cells positive to binding/internalization of HFt-MSH-PEG or HFt-PEG were evaluated in three randomly evaluated fields per sample at $20 \times$ magnification, and the average values are reported in Figure 2D. Four samples were examined for each type of construct and cells.

These results indicate that the $\alpha$-MSH targeting moiety effectively overcomes PEG masking and allows the HFtMSH-PEG constructs to recognize their target melanocortin receptors on melanoma cells specifically and that PEG molecules of the chosen length provide the HFt-MSH-PEG constructs with an effective shield against recognition by other cell types. It is important to point out that the HFtMSH-PEG derivatives were also able to be internalized by the target melanoma cells, which is a necessary property for potential therapeutic application. In contrast, in the lone previous report on HFt derivatives bearing an RGD peptide as a targeting moiety, evidence of construct internalization was not provided. ${ }^{26}$ Given that internalization is likely to be mediated by interaction of the exposed $\alpha-\mathrm{MSH}$ ligand with its cognate melanocortin receptor, the choice of tumor selector appears to be an essential factor to take into account in the rational design of nanoparticles for targeted delivery.

Finally, we performed a series of in vivo experiments using melanoma-bearing mice. Twenty-four hours after intracardiac injection, confocal microscopy performed on freshly harvested skin flaps, including tumor tissue, demonstrated marked accumulation of HFt-MSH-PEG constructs inside the melanoma tissue in all the skin layers examined, ie, epidermal, dermal, subdermal, and subcutaneous (Figure 3 and Supplementary Figure S10). Only an occasional weak signal from a few cells in the dermal/subcutaneous layers was observed, most likely from phagocytes. In contrast, wild-type HFt did not accumulate at tumor sites (Figure 3). As expected, some accumulation of HFt-MSH-PEG constructs was found also in Kupffer cells in the liver, but not 
A

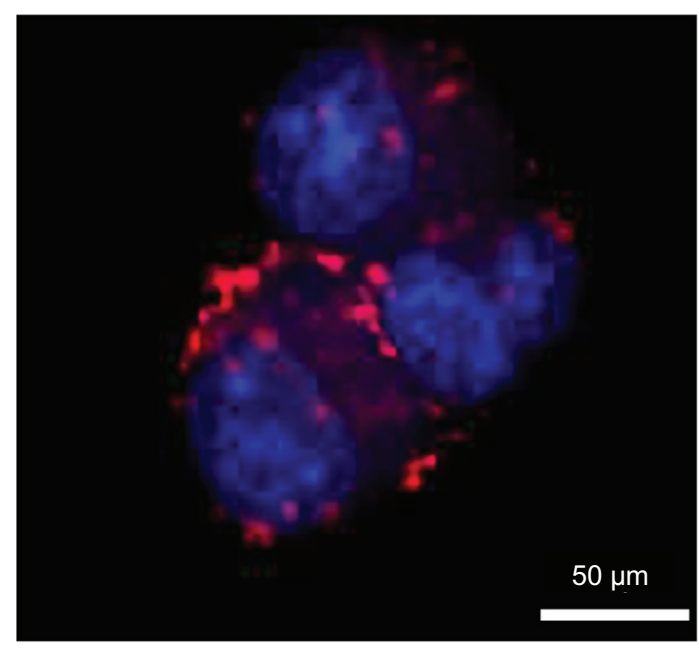

B

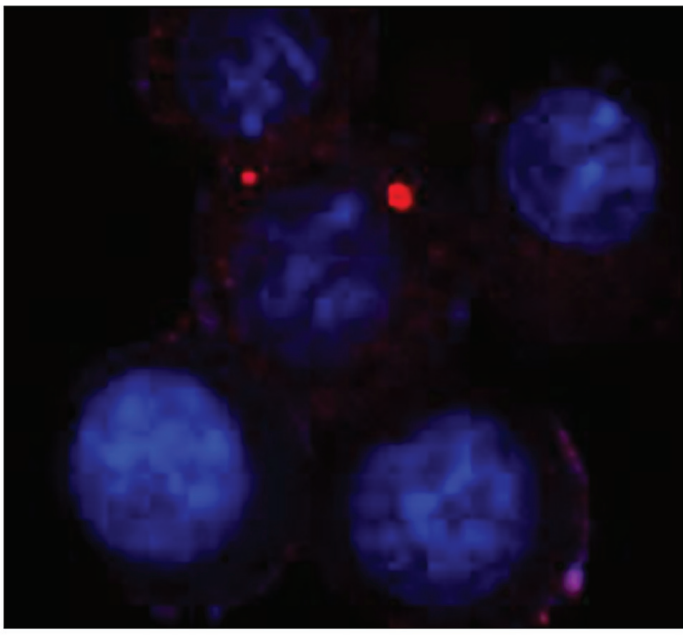

C

D
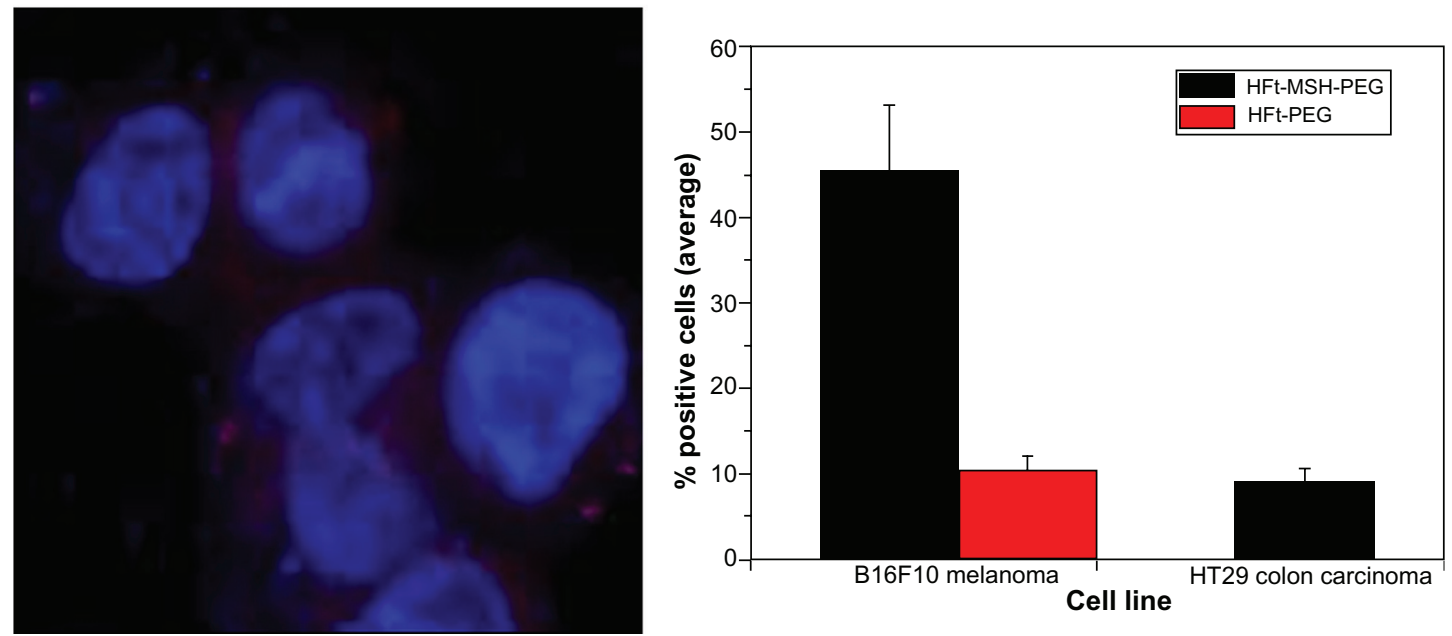

Figure 2 Laser-scanning confocal microscopy of mouse BI6FI0 melanoma (A and B) and human HT29 colon carcinoma (C) cells after one hour of incubation with HFt-MSH-PEG (A and C) or HFt-PEG (B) nanoparticles. Both types of nanoparticles were rhodamine-labeled. Clusters of HFt-based nanoparticles with rhodamine fluorescence appear in red. Original magnification 40x. Scale bar corresponds to all images. (D) Cell binding/internalization percentages assessed from the in vitro results. Average of positive cells in three randomly evaluated fields per sample at 20x magnification (four samples for each type of treatment and cells).

Abbreviations: HFt, human protein ferritin; PEG, polyethylene glycol; MSH, melanocyte-stimulating hormone peptide.

in hepatocytes. This result indicates that the HFt-MSH-PEG constructs have significantly higher target selectivity with respect to the previously reported HFt construct bearing an RGD peptide as the targeting moiety, accumulation of which was far greater in the liver than in the target glioma tumor. ${ }^{24}$ To our knowledge, this is the only HFt-based construct that has been previously studied in vivo.

We then investigated the in vitro plasma stability and in vivo circulation time of the HFt-based nanoparticles. For the plasma stability test, a size exclusion chromatography experiment using a GE Healthcare FPLC system Unicorn Akta purifier was undertaken to monitor the presence of intact nanoparticles after incubation in mouse plasma. The data reported in Table S1 demonstrate that both wild-type $\mathrm{HFt}$ and HFt-MSH-PEG nanoparticles have very high in vitro plasma stability, because they undergo very little degradation over 48 hours of incubation in mouse plasma (about $92 \%$ and $98 \%$ of intact protein, respectively). Clearance of HFt and HFt-MSH-PEG nanoparticles from the blood was investigated in vivo using Western blot analysis in healthy mice. HFt-MSH-PEG nanoparticles showed a significantly higher concentration and longer residence time in blood compared with wild-type HFt nanoparticles (Figure 4). In particular, HFt was absent after one hour, in accordance with previously reported data indicating clearance of HFt from the circulation in the 10-60 minutes following injection. ${ }^{28}$ In contrast, 


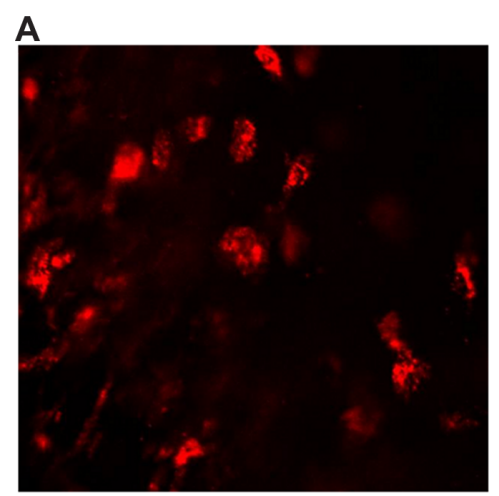

A

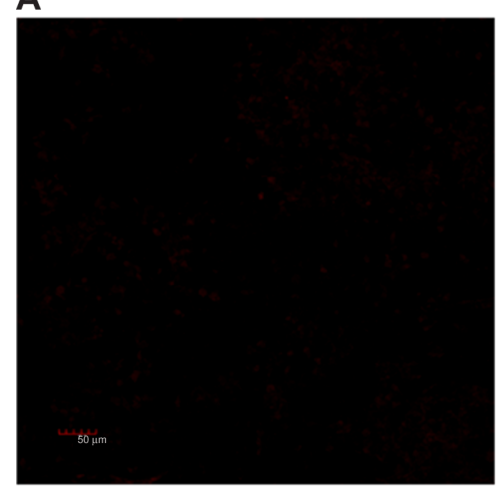

B

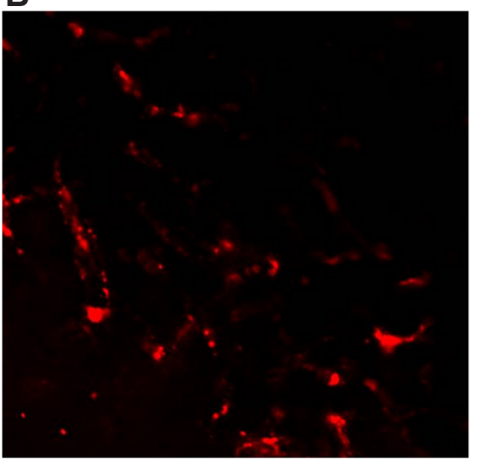

B

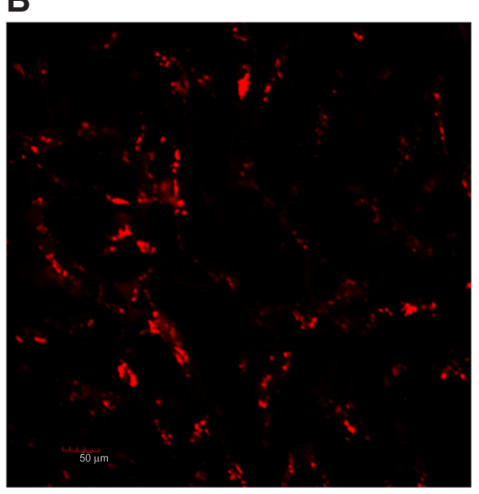

C

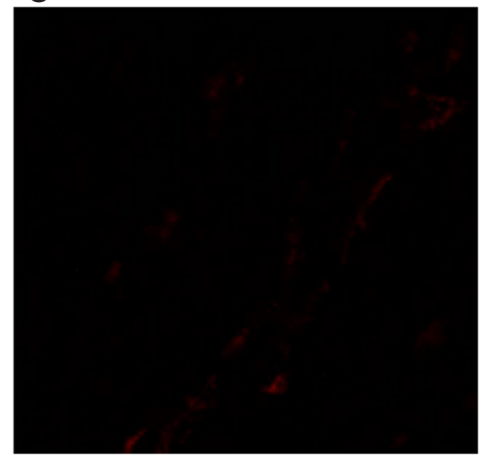

C

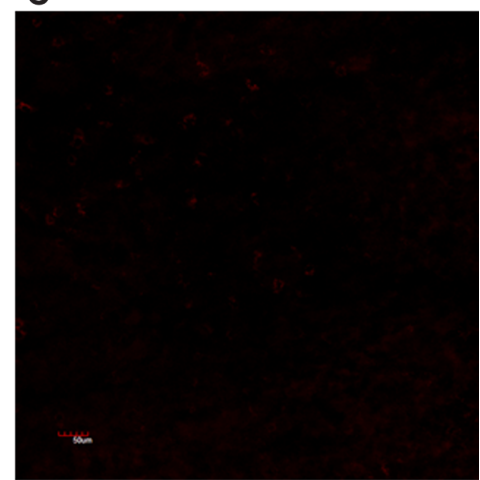

Figure 3 Laser scanning confocal microscopy on the freshly removed tumor (A), liver (B), and skin (C) 24 hours after intracardiac administration of rhodamine-labeled HFt-MSH-PEG (top) and wild-type HFt (bottom) nanoparticles. Melanoma BI6FI0 developed in mouse C57BL/6 with a 6 mm diameter. Original magnification 20×. Abbreviations: $\mathrm{HFt}$, human protein ferritin; PEG, polyethylene glycol; MSH, melanocyte-stimulating hormone peptide.

HFt-MSH-PEG showed significantly greater persistence in the circulation, being clearly visible for up to 6 hours and still detectable at 24 hours. Such differential blood kinetics are likely to contribute to the different biodistribution patterns observed for wild-type HFt and HFt-MSH-PEG.

In addition, very preliminary in vivo tests were performed to investigate the effect of HFt nanoparticles on immune cells. No significant changes in the percentages of immune cells present at 23-24 hours after in vivo administration of the nanoparticles in the murine model were observed. However, we found increased expression of the early activation marker, CD69, on all the leukocyte populations investigated (see Supplementary Figure S11). Activation by both HFt nanoparticles resulted to be generally higher in the spleen than in the blood, especially in the granulogate cells. Interestingly, activation of all groups of cells following administration of wild-type HFt was stronger than that induced by HFt-PEG-MSH nanoparticles. Although very preliminary, our results suggest that $\mathrm{HFt}$ nanoparticles exert some direct functional effects on leukocytes, possibly due to activation of phagocytosis, and that PEGylated HFt-MSH-PEG constructs have a weaker primary immunological stimulatory effect than wild-type
HFt, supporting the hypothesis that PEG molecules are an effective shield for the HFt protein. However, it is worth bearing in mind that while $\alpha-\mathrm{MSH}$ is completely conserved in humans and mice, murine HFt is not identical to the human homolog. Therefore, nanoparticles containing human HFt are expected to be more immunogenic in the mouse than in humans.

The high target selectivity, plasma stability, and a long circulation time observed for the HFt-MSH-PEG nanoparticles developed in this experiment indicate that these constructs can be exploited to develop HFt derivatives for application in the diagnosis and/or treatment of melanoma. For example, the HFt-MSH-PEG nanoparticles could be further engineered by chemically conjugating reactive groups on the external surface using temozolomide or dacarbazine by means of reversible cross-linkers, the bonding of which with the drug would be expected to be broken in the cytoplasm. Additionally, the internal cavity of HFt could be loaded with cisplatin, which has been shown to have cytotoxic activity when incorporated within commercial horse apoferritin, ${ }^{25}$ or ${ }^{64} \mathrm{Cu}$, which may be used for detection by PET. ${ }^{24}$ HFt-based constructs bearing these functionalities are currently being developed in our laboratory. 


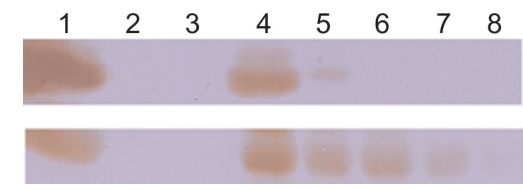

Figure 4 In vivo circulation time of HFt-based nanoparticles. HFt nanoparticles have been quantified by Western blot using an anti-MSH (bottom) and anti-HFt (top) antibody (see Materials and methods section). Lane I, reference proteins HFt-MSHPEG (bottom) and HFt (top), I mg/mL; lane 2, empty; lane 3, plasma before HFtnanoparticle injection; lanes 4-8, plasma at 3 minutes and I, 3, 6, and 24 hours following intracardiac injection.

Abbreviations: $\mathrm{HFt}$, human protein ferritin; $\mathrm{PEG}$, polyethylene glycol; $\mathrm{MSH}$, melanocytestimulating hormone peptide.

Further, the rational design of HFt-based nanoparticles as reported here is amenable to exploitation for selective delivery to a large number of different cell types, provided that a suitable targeting moiety is available. Targeting moieties that can be loaded onto the HFt nanoplatform include not only peptides, which can be genetically linked to the protein, but also molecules endowed with reactive groups, which can be conjugated with reactive amino and/ or carboxylate groups exposed on the HFt surface.

To evaluate the actual potential of targeted HFt-PEG constructs for clinical application and to assess whether PEGylation affects the main routes of ferritin protein excretion in the body (ie, the kidney and/or liver), ${ }^{33}$ further in vivo studies, including biodistribution in other relevant tissues, body clearance, toxicity, immunological effects, and the immunogenicity of our constructs will be performed.

\section{Conclusion}

In this work, we developed a rationally designed, genetically engineered, and chemically modified HFt-based multifunctional nanoplatform (HFt-MSH-PEG). These constructs were extensively characterized by taking advantage of an array of physicochemical techniques, and their targeting selectivity and plasma stability were assessed by in vitro and in vivo experiments, HFt-MSH-PEG were recognized and internalized specifically by melanoma cells, but not by other human tumor cells or mouse tissues (except for expected uptake by dedicated phagocytes), and were present for up to 24 hours in the bloodstream. The high target specificity of HFt-MSH-PEG is determined by the following: choice of a selective targeting moiety, namely the $\alpha$-MSH peptide, sufficiently exposed on the protein surface because of the presence of a peptide linker which binds receptors expressed only by melanoma cells and to a lesser extent by melanocytes; controlled modification of the HFt protein surface with PEG molecules of appropriate length, which mask the whole construct, except for the targeting $\alpha-\mathrm{MSH}$ peptide, from its physiological receptors; and significant reduction in nonspecific recognition and reduced uptake by the reticuloendothelial and mononuclear phagocytic systems.

The targeting strategy adopted in this work to produce HFt-MSH-PEG constructs can be implemented to develop HFt-based PEGylated nanoparticles containing targeted molecules for different cells and tissues. Further modification with cytotoxic and/or imaging agents would be required to produce molecules amenable to theragnostic applications. Selective nanoparticle accumulation at the sites of disease, as observed in this work, would allow tumors to be visible in the earlier stages, enabling improved diagnostic possibilities, and contribute to reduction of toxic side effects in normal tissue, thereby increasing the efficacy of chemotherapy. Indeed, we expect that the HFt functionalization strategy presented here will help overcome many of the current difficulties in the use of ferritin-based assemblies for in vivo applications and advance towards the development of protein-based nanoplatforms for effective diagnostic and therapeutic applications.

\section{Acknowledgments}

PC thanks the Associazione Italiana per la Ricerca sul Cancro, Milan, for funding under grant agreement MFAG10545 and the Italian Ministry of Economy and Finance for funding the Project "FaReBio di Qualità". LV acknowledges Fondazione Anna Villa e Felice Rusconi, Varese, for funding and IRC MBU AV0Z50200510. The authors thank Giovanni Luca Scaglione at the Università Cattolica del Sacro Cuore of Rome for the dynamic light scattering experiments and Zaneta Ruzickova at the Institute of Microbiology VVI, Academy of Sciences of the Czech Republic, in Prague (CZ) for technical assistance in confocal microscopy.

\section{Disclosure}

The authors report no conflicts of interest in this work.

\section{References}

1. Poon Z, Chang D, Zhao X, Hammond PT. Layer-by-layer nanoparticles with a $\mathrm{pH}$-sheddable layer for in vivo targeting of tumor hypoxia. ACS Nano. 2011;5(6):4284-4292.

2. Kateb B, Chiu K, Black KL, et al. Nanoplatforms for constructing new approaches to cancer treatment, imaging, and drug delivery: what should be the policy? Neuroimage. 2011;54 Suppl 1:S106-S124.

3. Nie S. Understanding and overcoming major barriers in cancer nanomedicine. Nanomedicine. 2010;5(4):523-528.

4. Armstead AL, Li B. Nanomedicine as an emerging approach against intracellular pathogens. Int J Nanomedicine. 2011;6(1):3281-3293.

5. Tzeng SY, Yang PH, Grayson WL, Green JJ. Synthetic poly(ester amine) and poly(amido amine) nanoparticles for efficient DNA and siRNA delivery to human endothelial cells. Int J Nanomedicine. 2011;6(1): 3309-3322.

6. Bode SA, Minten IJ, Nolte RJ, Cornelissen JJ. Reactions inside nanoscale protein cages. Nanoscale. 2011;3(6):2376-2389. 
7. Heddle JG. Protein cages, rings and tubes: useful components of future nanodevices? Nanotechnol Sci Appl. 2008;1:67-78.

8. Chiancone E, Ceci P, Ilari A, Ribacchi F, Stefanini S. Iron and proteins for iron storage and detoxification. Biometals. 2004;17(3):197-202.

9. Watt RK. The many faces of the octahedral ferritin protein. Biometals. 2011;24(3):489-500.

10. Niemeyer CM, Ceyhan B. DNA-directed functionalization of colloidal gold with proteins. Angew Chem Int Ed Engl. 2001;40(19): 3685-3688.

11. Uchida M, Kang S, Reichhardt C, Harlen K, Douglas T. The ferritin superfamily: supramolecular templates for materials synthesis. Biochim Biophys Acta. 2010;1800(8):834-845.

12. Dominguez-Vera JM, Fernandez B, Galvez N. Native and synthetic ferritins for nanobiomedical applications: recent advances and new perspectives. Future Med Chem. 2010;2(4):609-618.

13. Kasyutich O, Ilari A, Fiorillo A, Tatchev D, Hoell A, Ceci P. Silver ion incorporation and nanoparticle formation inside the cavity of Pyrococcus furiosus ferritin: structural and size-distribution analyses. JAm Chem Soc. 2010;132(10):3621-3627.

14. Li M, Viravaidya C, Mann S. Polymer-mediated synthesis of ferritinencapsulated inorganic nanoparticles. Small. 2007;3(9):1477-1481.

15. Ueno T, Suzuki M, Goto T, Matsumoto T, Nagayama K, Watanabe $Y$. Size-selective olefin hydrogenation by a Pd nanocluster provided in an apo-ferritin cage. Angew Chem Int Ed Engl. 2004;43(19):2527-2530.

16. Yoshimura H. Protein-assisted nanoparticle synthesis. Colloids Surf A 2006;282-283(0):464-470.

17. Yamashita I. Biosupramolecules for nano-devices: biomineralization of nanoparticles and their applications. J Mater Chem. 2008;18(32): 3813-3820.

18. Kostiainen MA, Ceci P, Fornara M, et al. Hierarchical self-assembly and optical disassembly for controlled switching of magnetoferritin nanoparticle magnetism. ACS Nano. 2011;5(8):6394-6402.

19. Bakoush O, Tencer J, Tapia J, Rippe B, Torffvit O. Higher urinary IgM excretion in type 2 diabetic nephropathy compared to type 1 diabetic nephropathy. Kidney Int. 2002;61(1):203-208.

20. Jain RK. Delivery of molecular and cellular medicine to solid tumors. Adv Drug Deliv Rev. 2001;46(1-3):149-168.

21. Uchida M, Willits DA, Muller K, et al. Intracellular distribution of macrophage targeting ferritin-iron oxide nanocomposite. Adv Mater. 2009;21(4):458-462.

22. Valero E, Tambalo S, Marzola P, et al. Magnetic nanoparticle-templated assembly of protein subunits: a new platform for carbohydrate-based MRI nanoprobes. J Am Chem Soc. 2011;133(13):4889-4895.

23. Geninatti CS, Crich S, Bussolati B, et al. Magnetic resonance visualization of tumor angiogenesis by targeting neural cell adhesion molecules with the highly sensitive gadolinium-loaded apoferritin probe. Cancer Res. 2006;66(18):9196-9201.

24. Lin X, Xie J, Niu G, et al. Chimeric ferritin nanocages for multiple function loading and multimodal imaging. Nano Lett. 2011;11(2): 814-819.

25. Xing R, Wang $X$, Zhang $C$, et al. Characterization and cellular uptake of platinum anticancer drugs encapsulated in apoferritin. J Inorg Biochem. 2009;103(7):1039-1044

26. Uchida M, Flenniken ML, Allen M, et al. Targeting of cancer cells with ferrimagnetic ferritin cage nanoparticles. JAm Chem Soc. 2006;128(51): $16626-16633$.
27. Barreto JA, O’Malley W, Kubeil M, Graham B, Stephan H, Spiccia L. Nanomaterials: applications in cancer imaging and therapy. Adv Mater. 2011;23(12):H18-H40.

28. Worwood M, Cragg SJ, Williams AM, Wagstaff M, Jacobs A. The clearance of 131I-human plasma ferritin in man. Blood. 1982;60(4): 827-833.

29. Chen TT, Li L, Chung DH, et al. TIM-2 is expressed on B cells and in liver and kidney and is a receptor for $\mathrm{H}$-ferritin endocytosis. $J$ Exp Med. 2005;202(7):955-965.

30. Uchida $\mathrm{M}$, Terashima $\mathrm{M}$, Cunningham $\mathrm{CH}$, et al. A human ferritin iron oxide nano-composite magnetic resonance contrast agent. Magn Reson Med. 2008;60(5):1073-1081.

31. Mack U, Storey EL, Powell LW, Halliday JW. Characterization of the binding of ferritin to the rat liver ferritin receptor. Biochim Biophys Acta. 1985;843(3):164-170.

32. Fisher J, Devraj K, Ingram J, et al. Ferritin: a novel mechanism for delivery of iron to the brain and other organs. Am J Physiol Cell Physiol. 2007;293(2):C641-C649.

33. Anderson JG, Ramm GA, Halliday WJ, Powell WL. Ferritin metabolism in hemochromatosis. In: Barton JC, Edwards CQ, editors. Hemochromatosis: Genetics, Pathophysiology, Diagnosis and Treatment. Cambridge, UK: Cambridge University Press; 2000.

34. Fittipaldi $\mathrm{M}$, Innocenti $\mathrm{C}$, Ceci $\mathrm{P}$, et al. Looking for quantum effects in magnetic nanoparticles using the molecular nanomagnet approach. Physical Review B. 2011;83(10):104409.

35. Benada O, Pokorny V. Modification of the Polaron sputter-coater unit for glow-discharge activation of carbon support films. J Electron Microsc Tech. 1990;16(3):235-239.

36. Berman HM, Westbrook J, Feng Z, et al. The protein data bank. Nucleic Acids Res. 2000;28(1):235-242.

37. Ballou B, Lagerholm BC, Ernst LA, Bruchez MP, Waggoner AS. Noninvasive imaging of quantum dots in mice. Bioconjug Chem. 2004; 15(1):79-86.

38. Raha S, Paunesku T, Woloschak G. Peptide-mediated cancer targeting of nanoconjugates. Wiley Interdiscip Rev Nanomed Nanobiotechnol. 2011;3(3):269-281.

39. Miao Y, Whitener D, Feng W, Owen NK, Chen J, Quinn TP. Evaluation of the human melanoma targeting properties of radiolabeled alphamelanocyte stimulating hormone peptide analogues. Bioconjug Chem. 2003;14(6):1177-1184.

40. Tatro JB, Atkins M, Mier JW, et al. Melanotropin receptors demonstrated in situ in human melanoma. $J$ Clin Invest. 1990;85(6):1825-1832.

41. Miao Y, Quinn TP. Peptide-targeted radionuclide therapy for melanoma. Crit Rev Oncol Hematol. 2008;67(3):213-228.

42. Balch CM, Soong SJ, Gershenwald JE, et al. Prognostic factors analysis of 17,600 melanoma patients: validation of the American Joint Committee on Cancer melanoma staging system. J Clin Oncol. 2001; 19(16):3622-3634.

43. Lu W, Xiong C, Zhang G, et al. Targeted photothermal ablation of murine melanomas with melanocyte-stimulating hormone analog-conjugated hollow gold nanospheres. Clin Cancer Res. 2009;15(3):876-886. 


\section{Supplementary figures}

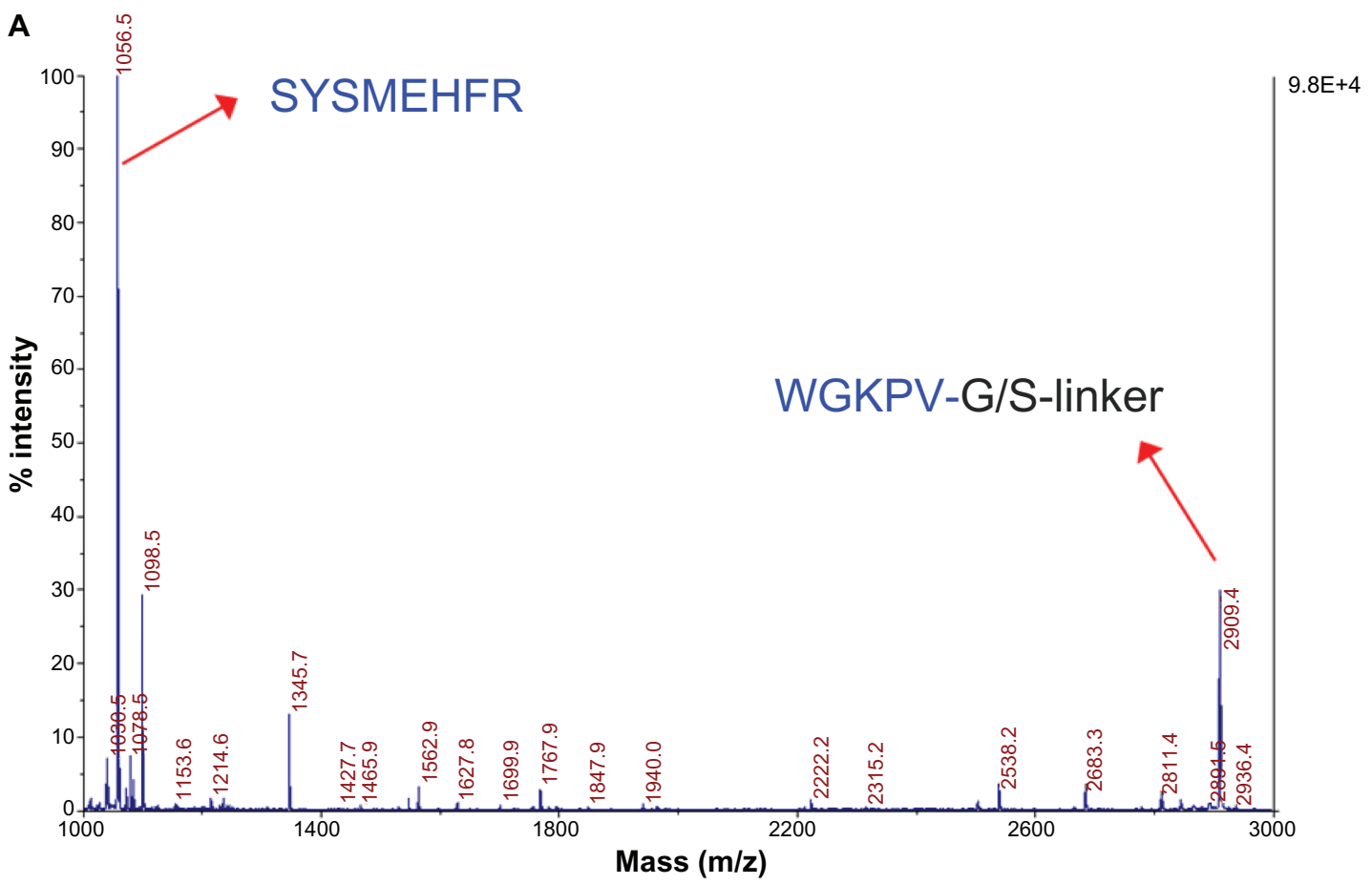

B

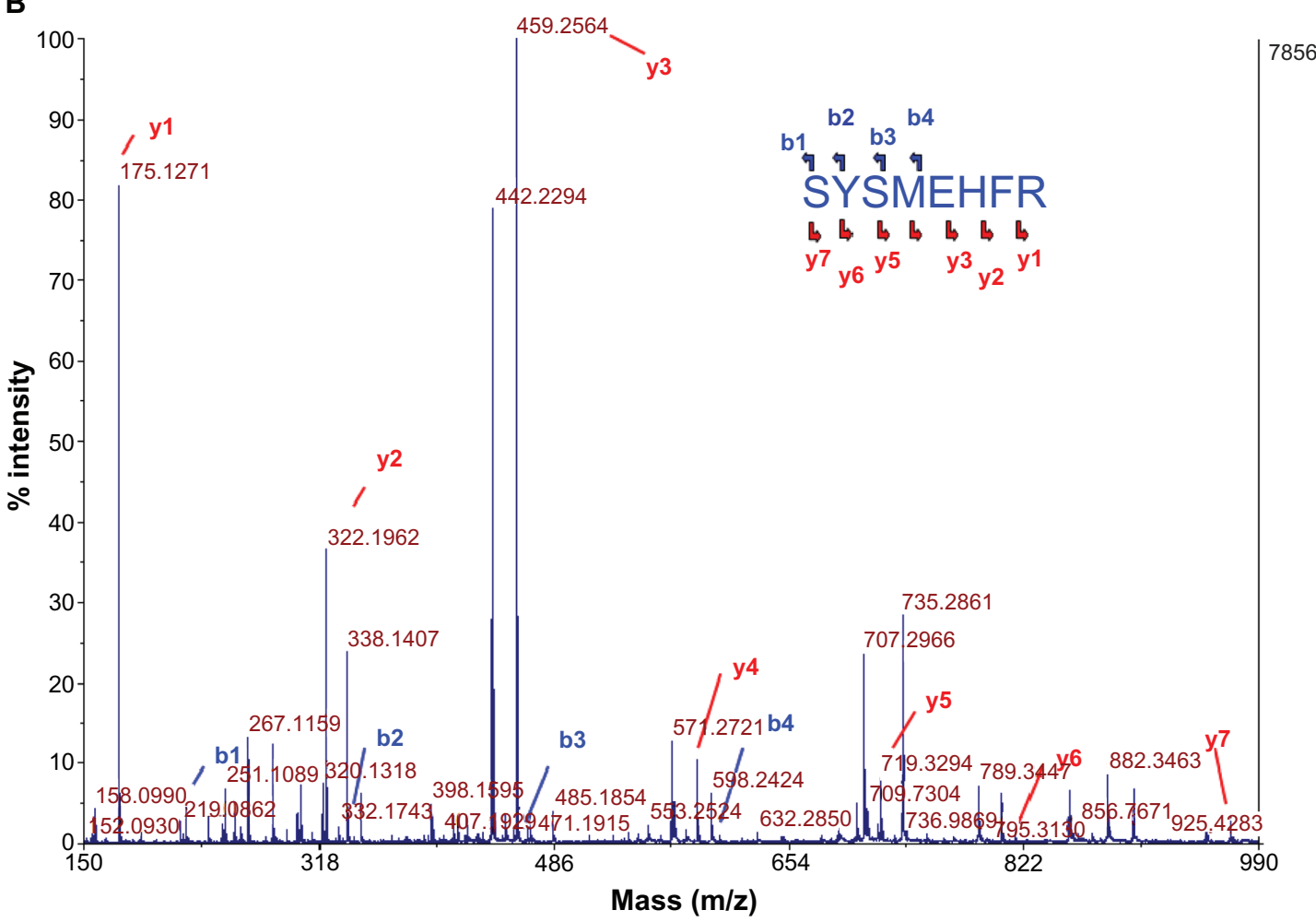

Figure SI (A) MALDI-MS spectrum of the native HFt-MSH-PEG trypsin digests. Peaks corresponding to the MSH and linker amino acid sequences at the protein N-termini are indicated with red arrows. (B) MALDI-MS/MS spectrum of the $\mathrm{m} / \mathrm{z} 1056.5$ peak reported in (A).

Notes: The fragmentation sites along the peptide (SYSMEHFR) backbone corresponding to the observed peaks are indicated by arrows, and the arrow direction indicates the charge-retaining portion. Peaks corresponding to the expected masses for the $y$ and $b$ ions are indicated by the relative ion name.

Abbreviations: $\mathrm{HFt}$, human protein ferritin; PEG, polyethylene glycol; MSH, melanocyte-stimulating hormone peptide; MALDI, matrix-assisted laser desorption ionization; MS, mass spectrometry. 

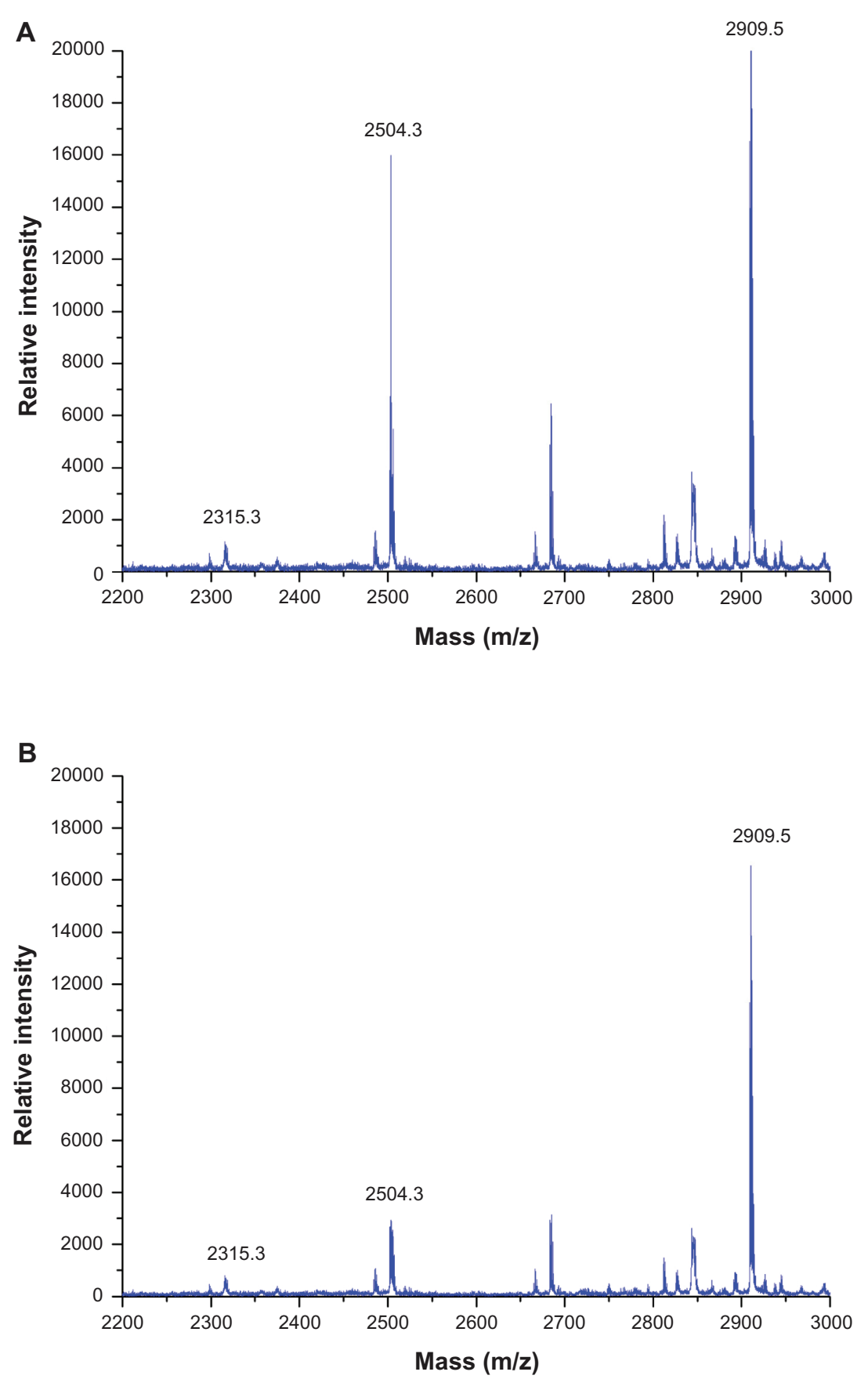

Figure S2 MALDI-MS spectrum (range 2200-3000 m/z) of the native HFt-MSH (A) and HFt-MSH-PEG (B) trypsin digests.

Notes: Peaks matching to the protein sequences are reported. The $\mathrm{m} / \mathrm{z} 2504.3$ peak corresponds to the KPDCDDWESGLNAMECALHLEK sequence and it is expected to react with and bind to PEG-maleimide molecules due to the presence of two cysteine residues. From mass analysis, a decrease of the peak corresponding to this peptide was observed, but a heavier peak at about 12,000-13,000 m/z did not appear, likely because of poor flying ability due to the conjugation with PEG molecules.

Abbreviations: HFt, human protein ferritin; PEG, polyethylene glycol; MSH, melanocyte-stimulating hormone peptide; MALDI, matrix-assisted laser desorption ionization; MS, mass spectrometry. 


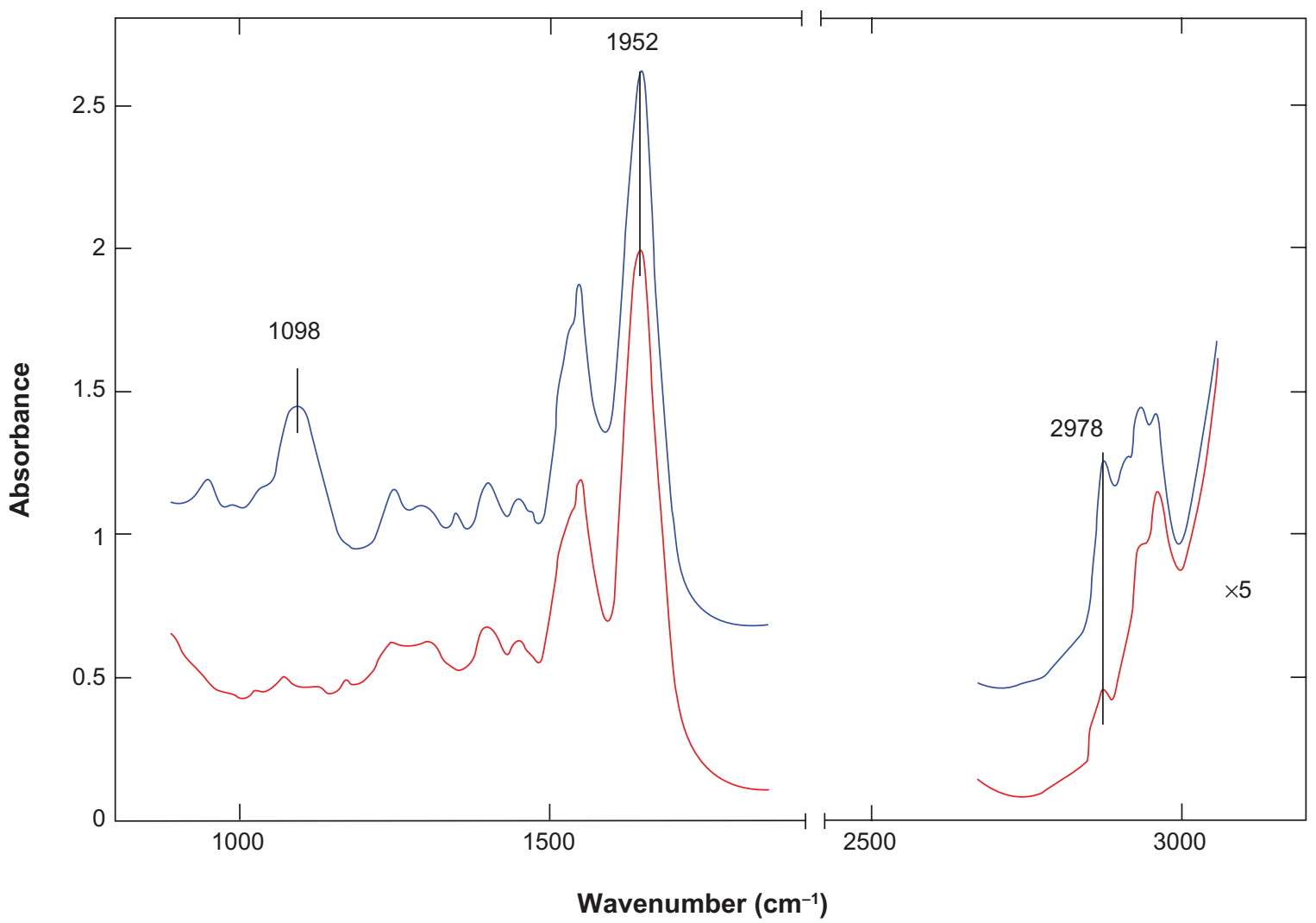

Figure S3 Attenuated total reflectance-Fourier transform infrared spectra of apo-HFt-MSH (red) and PEGylated apo-HFt-MSH-PEG (blue).

Notes: The spectra have been obtained on fully hydrated samples in attenuated total reflectance mode on a $\mathrm{ZnSe}$ plates at $4 \mathrm{~cm}^{-1}$ resolution and $25^{\circ} \mathrm{C}$. Spectra were subtracted by the contribution of the clean and empty attenuated total reflectance plates. Details of the low frequency region highlight the presence of the $\mathrm{PEG}\left(\mathrm{CH}_{2}-\mathrm{O}-\mathrm{CH}_{2}\right)$ stretching modes at $1098 \mathrm{~cm}^{-1}$ (top spectrum) in the PEGylated apo HFt-MSH. The contribution of the PEG (H-C-H) stretching modes is also manifest in the increased absorbance at $2978 \mathrm{~cm}^{-1}$ in the PEGylated protein (top spectrum).

Abbreviations: HFt, human protein ferritin; PEG, polyethylene glycol; MSH, melanocyte-stimulating hormone peptide; MALDI, matrix-assisted laser desorption ionization.
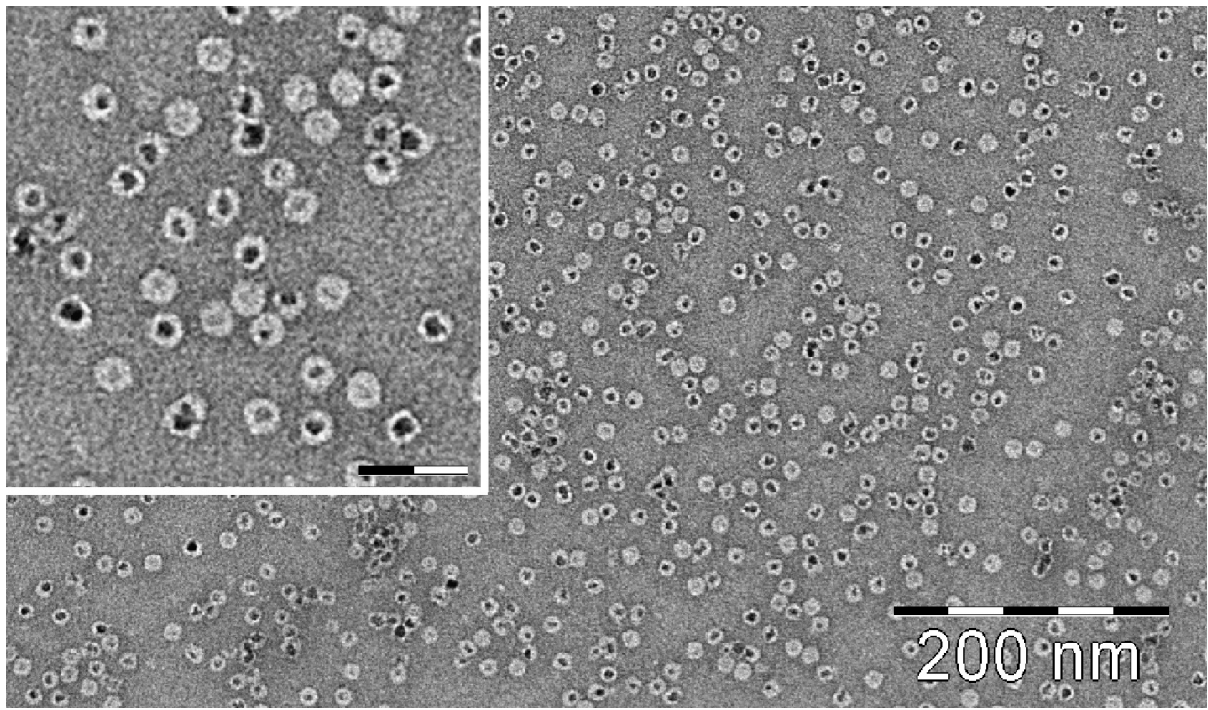

Figure S4 TEM image of magnetite/maghemite-containing HFt-MSH showing the metallic core (black) surrounded by the HFt shell (white). Inset: $2.5 \times$ magnified image, scale bar $32 \mathrm{~nm}$.

Abbreviations: $\mathrm{HFt}$, human protein ferritin; $\mathrm{MSH}$, melanocyte-stimulating hormone peptide. 
A
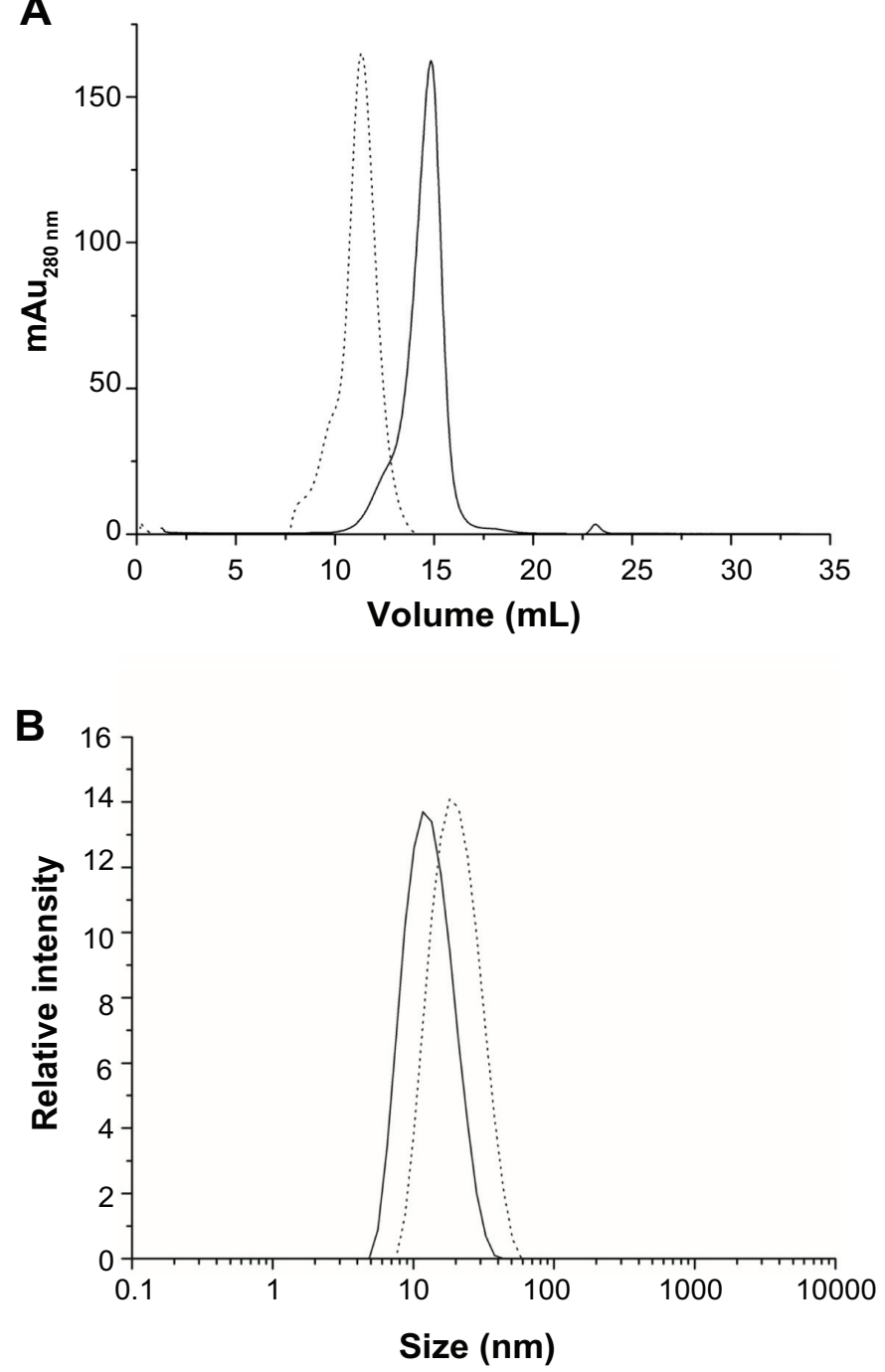

Figure S5 (A) Size exclusion chromatography and (B) dynamic light scattering profiles of HFt before (solid line) and after (dotted lines) the PEGylation reaction. Abbreviations: $\mathrm{HFt}$, human protein ferritin; $\mathrm{PEG}$, polyethylene glycol.

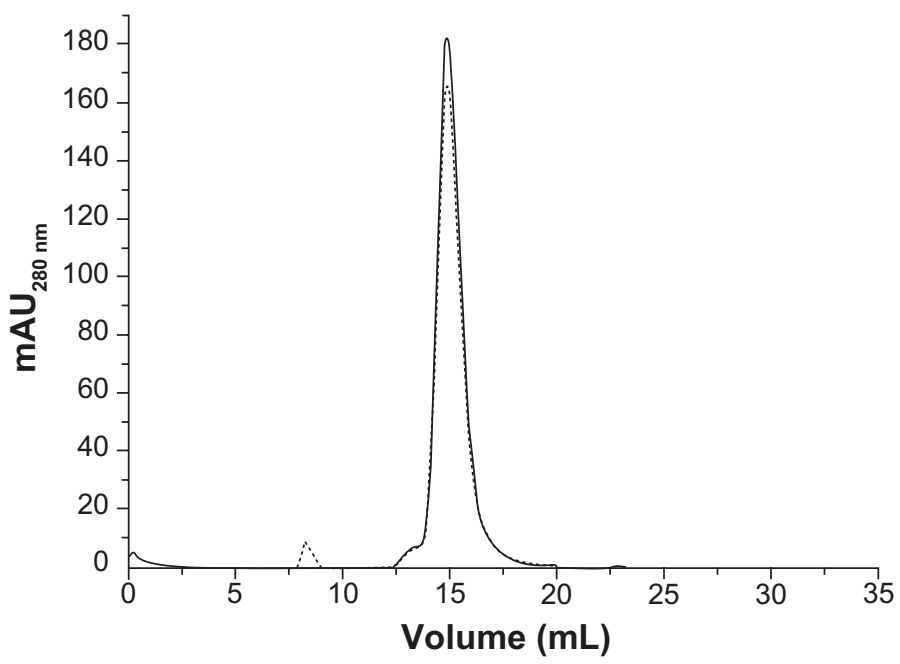

Figure S6 Size exclusion chromatography profiles of HFt-MSH before (solid line) and after (dotted lines) the pH jump experiment (see Material and methods section). Abbreviations: $\mathrm{HFt}$, human protein ferritin; $\mathrm{MSH}$, melanocyte-stimulating hormone peptide. 


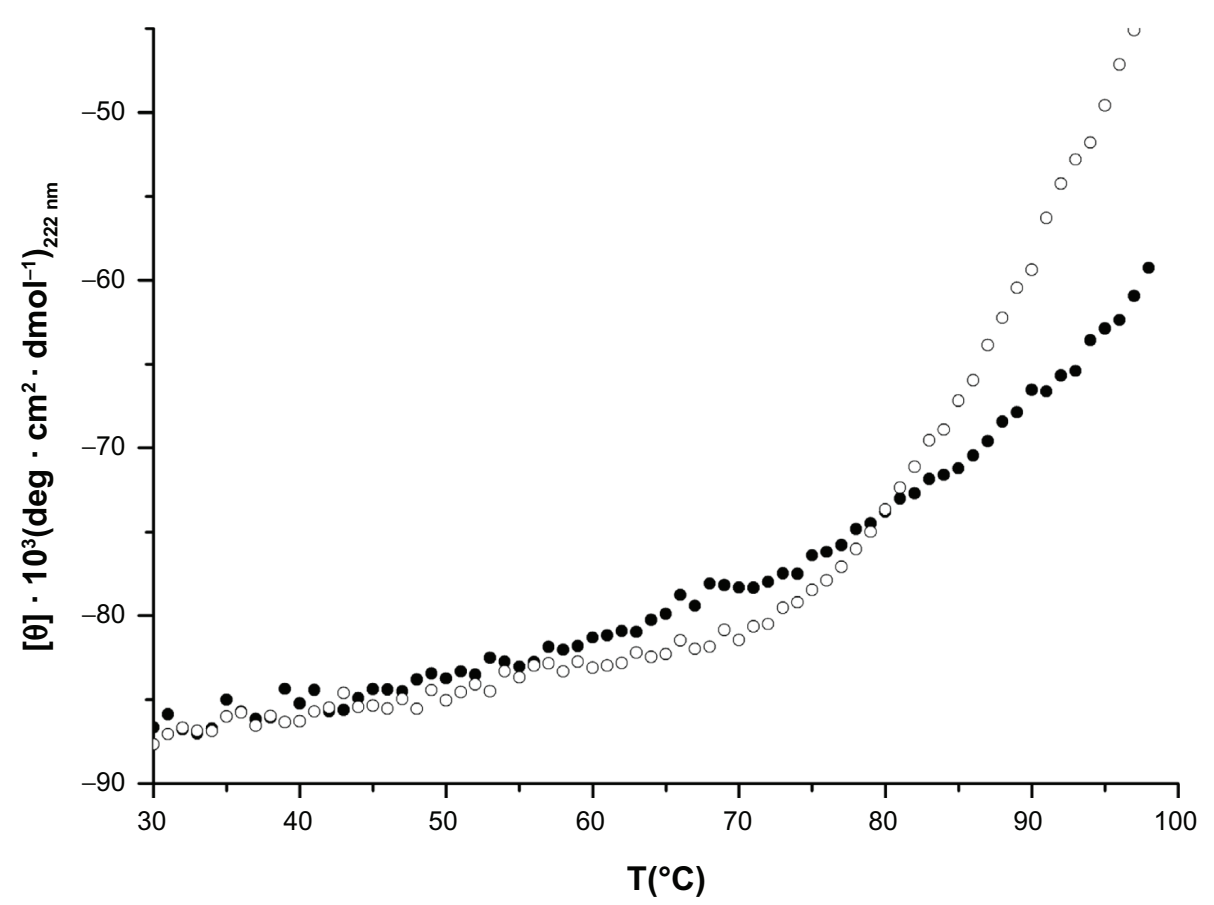

Figure S7 Thermal denaturation of HFt (open circle) and HFt-MSH (black circle).

Notes: Spectra were recorded at $222 \mathrm{~nm}$ in 0.1 quartz cuvettes. Protein concentration was I mg/mL in $\mathrm{H}_{2} \mathrm{O}_{\text {dd }}$.

Abbreviations: $\mathrm{HFt}$, human protein ferritin; $\mathrm{MSH}$, melanocyte-stimulating hormone peptide.
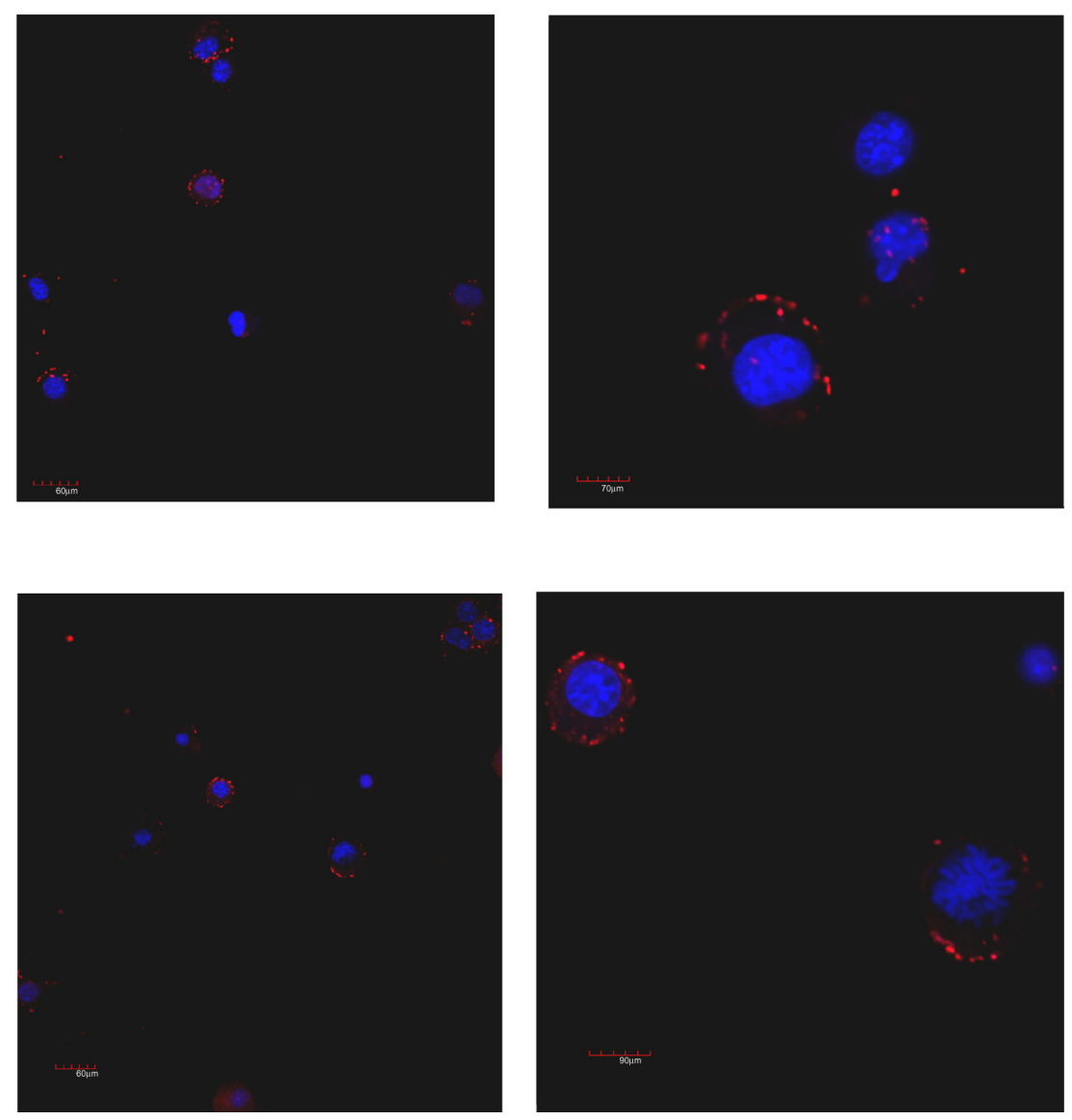

Figure S8 Laser-scanning confocal microscopy of mouse BI6FI0 melanoma cells after 10 (top) and 60 (down) minutes of incubation with HFt rhodamine-labeling. Notes: Clusters of HFt-based nanoparticles with rhodamine fluorescence appear in red. Original magnification $40 \times($ left) and zoom $3 \times(I 20 \times$, right) were used. Abbreviations: $\mathrm{HFt}$, human protein ferritin; $\mathrm{MSH}$, melanocyte-stimulating hormone peptide. 

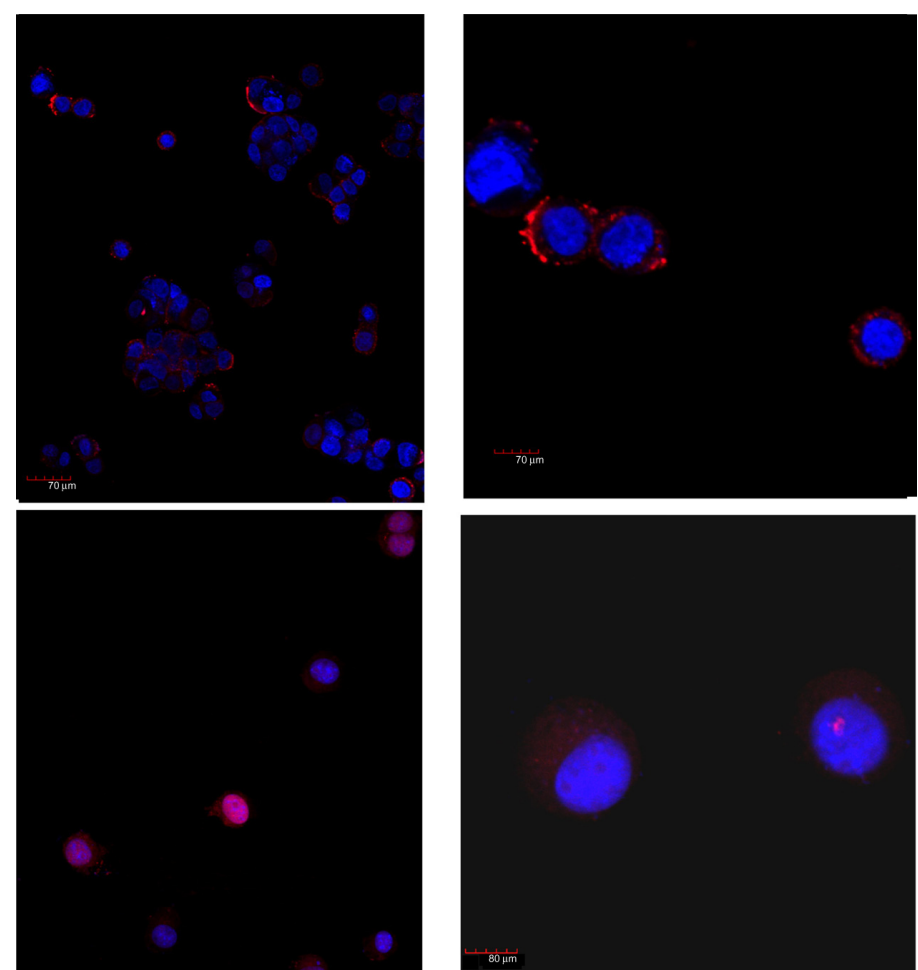

Figure S9 Laser scanning confocal microscopy of human HT29 colon carcinoma cells after 10 (top) and 60 (down) minutes of incubation with HFt rhodamine-labeling. Clusters of HFt-based nanoparticles with rhodamine fluorescence appear in red.

Note: Original magnification $40 \times$ (left) and zoom $3 \times($ I $20 \times$, right) were used.

Abbreviation: $\mathrm{HFt}$, human protein ferritin.

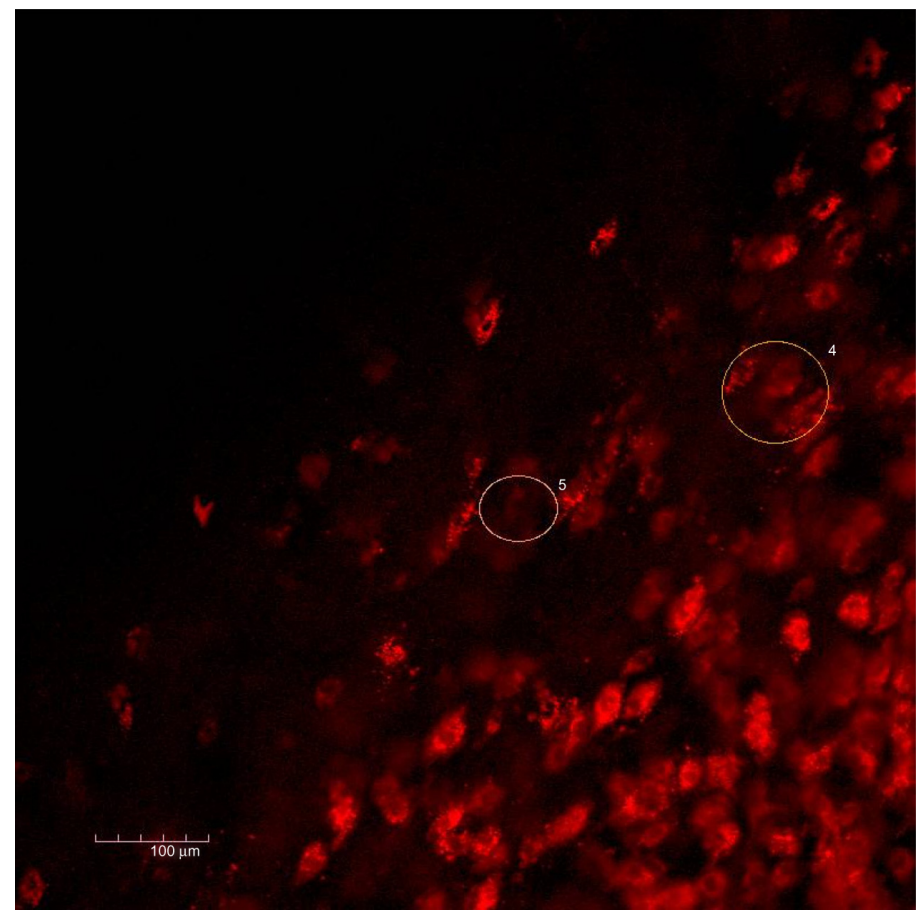

Figure SI 0 Melanoma and skin

Notes: Representative image from a Z series of 46 images, $0.8 \mu \mathrm{m}$ space, taken at the border of the tumor. The specific uptake of HFt-MSH-PEG nanoparticles by the tumor cells but not by the surrounding tissue was evident in all images. The tumor was initially sectioned to be leveled to the surrounding tissue and allow effective evaluation of both tissues on the same layer (confocal microscopy, $20 \times$ original magnification, nanoparticles fluorescence in red, numbers indicate areas that were selected for further imaging analysis, first image).

Abbreviations: HFt, human protein ferritin; PEG, polyethylene glycol; MSH, melanocyte-stimulating hormone peptide. 

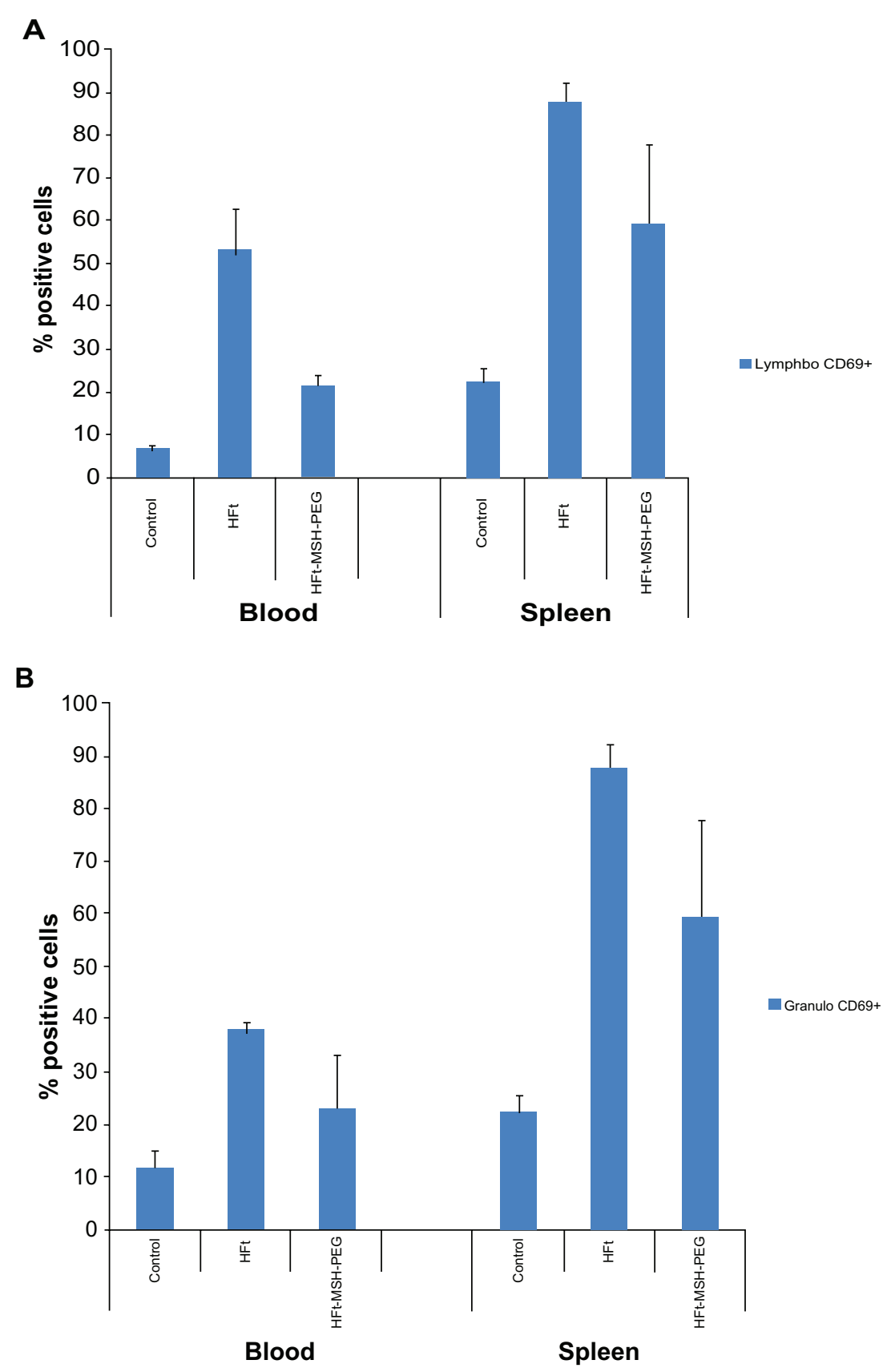

Figure SI I Percentages of CD69-positive cells in two gated populations of leukocytes (granulogates, lymphogates, and monogates) from peripheral blood and spleen cells, evaluated at 23 hours after administration of HFt-nanoparticles in healthy mice (three animals per group).

Abbreviation: HFt, human protein ferritin. 
Table SI Stability of HFt and HFt-MSH-PEG nanoparticles in human plasma

\begin{tabular}{lll}
\hline Time (hours) & HFt & HFt-MSH-PEG \\
\hline$\%$ of intact protein & 100 & 100 \\
Initial & 93 & 99 \\
1 & 92 & 98 \\
6 & 92 & 98 \\
18 & 92 & 98 \\
24 & 92 & 98 \\
48 & 92 & \\
\hline
\end{tabular}

Abbreviations: HFt, human protein ferritin; PEG, polyethylene glycol; MSH, melanocyte-stimulating hormone peptide.

\section{Publish your work in this journal}

The International Journal of Nanomedicine is an international, peerreviewed journal focusing on the application of nanotechnology in diagnostics, therapeutics, and drug delivery systems throughout the biomedical field. This journal is indexed on PubMed Central,

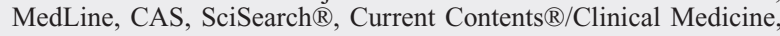

Journal Citation Reports/Science Edition, EMBase, Scopus and the Elsevier Bibliographic databases. The manuscript management system is completely online and includes a very quick and fair peer-review system, which is all easy to use. Visit http://www.dovepress.com/ testimonials.php to read real quotes from published authors.

Submit your manuscript here: http://www.dovepress.com/international-journal-of-nanomedicine-journal 